\title{
Report of a WHO Scientific Group
}

Introduction 6

Nature of Cell-Mediated Immunity
8

8

Induction of Cell-Mediated Immunity

Cells Involved in the Expression of Cell-Mediated Immunity

Expression of Cell-Mediated Immunity

Interactions between Antibody-Mediated and Cell-Mediated Immunity... 25

3. Characteristics of Cell-Mediated Resistance to Various Types of Infection ...

Bacterial Infections 29

Virus Infections 32

Mycoplasma Infections

32

Fungus Infections $\quad 37$

Protozoal Infections $\quad 39$

Metazoal Infections 43

4. Aberrant or Defective Functioning of Cell-Mediated Immunity

Nonspecific Unresponsiveness

44

47

Antigen-Specific Unresponsiveness

49

Granuloma Formation

Cell-Mediated Immunity in Clinical Diagnosis and Treatment

Diagnostic Measures Based on Cell-Mediated Immune Reactions

Augmentation of the Immune Response

56

6. Prophylaxis 58

Annex: Further Background Literature

60

WHO Scientific Group on Cell-Mediated Immunity and Resistance to Infection Geneva, 19-23 September 1972

Members

Dr. A. C. Allison, Clinical Research Centre, Northwick Park Hospital, Harrow,

England (Vice-Chairman) Prof. B. R. Bloom, Department of Microbiology and Immunology, Albert Einstein

College of Medicine, Yeshiva University, Bronx, N.Y., USA Dr. T. Brunner, Swiss Institute for Experimental Cancer Research, Lausanne,

Switzerland Dr. T. Godal, Armauer Hansen Research Institute, Addis Ababa, Ethiopia Dr. G. B.

Mackaness, Trudeau Institute, Saranac Lake, N.Y., USA (Chairman) Dr. D. D. McGregor,

Trudeau Institute, Saranac Lake, N.Y., USA (Rapporteur) Dr. D. S. Nelson, Department of

Bacteriology, University of Sydney, Australia Prof. J. L. Turk, Department of Pathology, Royal

College of Surgeons, London,

England

Secretariat1 
Dr. R. V. Blanden, John Curtin School of Medical Research, Australian National University, Canberra, Australia (Temporary Adviser)

Dr. W. P. Faulk, Immunology, WHO, Geneva, Switzerland

Dr. H. C. Goodman, Chief, Immunology, WHO, Geneva, Switzerland (Secretary)

Dr. J. S. Remington, Allergy, Immunology and Infectious Diseases Department, Palo Alto

Medical Research Foundation, Calif., USA (Temporary Adviser)

Dr. J. N. Sheagren, College of Medicine, Department of Medicine, Howard University,

Washington, D.C., USA (Temporary Adviser)

Dr. G. Torrigiani, Immunology, WHO, Geneva, Switzerland

1 Unable to attend: Dr. B. D. Brondz, Gamaleja Institute of Epidemiology and Microbiology, Moscow, USSR. 1973;044:585

Cell-Mediated Immunity and Resistance to Infection

Report of a WHO Scientific Group

A WHO Scientific Group on Cell-Mediated Immunity and Resistance to Infection met in Geneva from 19 to 23 September 1972. The meeting was opened on behalf of the Director-General by

Dr. M. A. Akhmeteli, Director of the Division of Non-Communicable Diseases.

1. Introduction

In the early years of this century serum antibodies were shown to carry out many important protective functions, sometimes in conjunction with the complement system, e.g., neutralization of viruses, lysis of certain micro-organisms, or their opsonization for more efficient phagocytosis. Experience in human populations soon confirmed experimental observations indicating that antibody acted as a protective agent in a variety of infections. However, a group of diseases remained in which humoral immunity could not be demonstrated to influence host resistance. Tuberculosis, a notable example of such a disease, was distinguished by an additional peculiarity that had long puzzled immunologists. It was accompanied by an unusual delayed form of hypersensitivity that Zinsser first recognized in 1921 to be a feature of several other infectious diseases as well. Although delayed hypersensitivity to tuberculin was part of the Koch phenomenon and seemed to be a defensive reaction of some sort, its precise role remained a mystery for many years. Failure to transfer the reaction by the transfusion of antibody-containing serum deepened the mystery and pointed to a possible separate mechanism of immunity.

The event that opened the way to further progress in studying both im-

Report of a WHO Scientific Group

591

munity to organisms such as the tubercle baccillus and the nature of the delayed-type hypersensitivity engendered by this class of infectious agent was the demonstration by Chase \& Landsteiner in 1942 that such hypersensitivity could be conferred on non-reactive subjects by transferring living lymphoid cells from sensitized donors. These observations provided the foundation for the science of cellular immunology.

The past few years have brought a wave of new knowledge about the cells that constitute the body's immunological apparatus. The most notable advance has been the demonstration that there are two types of lymphocyte each having distinctive properties and different functions. Thy-mus-dependent lymphocytes ( $\mathrm{T}$ lymphocytes, or T cells), which arise from stem cells in the bone marrow and mature under the influence of the thymus, circulate throughout the body and respond to specific antigenic stimulation but do not secrete antibody. T lymphocytes are known to participate in at least 4 immune processes: rejection of allografts and tumours; delayed-type 
hypersensitivity reactions; activation of macrophages to resist infection; and a cooperative function with the precursors of antibody-forming cells that serves to increase antibody formation. The other class of lymphocytes - bone-marrow derived, thymus-independent lymphocytes (B lymphocytes, or B cells) and the cells derived from them -contribute to immunity by their unique capacity to synthesize and secrete antibodies.

Together with the availability of inbred strains that permit cell transfers between animals, this new knowledge concerning the cells involved in immunological processes has made it possible to analyse resistance to infectious diseases at the cellular level. This report is primarily concerned with cell-mediated immunity, i.e., with the cells that provide both a means of detecting a microbial invasion and a mechanism for resisting it without the secretion of antibody. But T cells, B cells, and antibodies interact in complex ways. While the mechanisms of humoral and cell-mediated immunity may be separated for purposes of analysis in most infectious diseases, they can act in concert to protect the host against extracellular and intracellular pathogens. The interplay between humoral and cellular immunity may also be associated with the contrasting forms of some infectious diseases, such as leprosy, and may contribute to the persistence or recurrence of others.

To investigate these complex problems new methods have been devised for studying cellmediated immune reactions in vitro. The serologi-cal techniques of the past are being complemented by a new and more

592 Cell-Mediated Immunity and Resistance to Infection sophisticated technology for manipulating living cells in vitro. The judicious use of these new techniques combined with a thoughtful application of older ones is gradually disclosing the basic mechanisms of defence against an ever-increasing number of infectious diseases. Every infectious disease is a distinct entity with its own particular features and each must be studied separately so that appropriate prophylactic and therapeutic procedures can be developed and tested.

2. Nature of Cell-Mediated Immunity 2.1 Induction of Cell-Mediated Immunity Acquired resistance to infectious disease begins with the induction of a specific immune response. The precise mechanisms of the inductive process are under intensive study and constitute one of the most important issues in immunology, but for the purpose of this report it is sufficient to say that induction involves some interaction between antigen and immunocompetent lymphocytes, with a possible intermediate step consisting in the processing or presentation of antigen by macrophages.

As stated above, the cell-mediated immune response involves $\mathrm{T}$ cells in particular. The properties of antigen-sensitive (progenitor) $\mathrm{T}$ cells and the possible influence of $\mathrm{B}$ cells or humoral antibody on the induction of the T cell response will be discussed in more detail subsequently. In this section we are concerned with the way in which antigens must be presented in order to provoke a $\mathrm{T}$ cell response, for it has long been known that special conditions of immunization are often required. For example, living intracellular parasites are noted for their ability to evoke a $\mathrm{T}$ cell response, as evidenced by the regular occurrence of delayed-type hypersensi-tivity - an external sign of T cell involvement - in infected animals and man. In contrast, killed vaccines or antigen extracts containing some of the same antigenic determinants as the living organisms fail to provoke cell-mediated immunity unless incorporated in Freundtype adjuvants. The reasons for this difference are not known, but there are several possible explanations, (a) Antigens released from infected macrophages may differ physicochemically from those released from macrophages that have ingested dead organisms. There is evidence that 
chemically-modified [Parish, 1971] or enzymatically-degraded flagellin [Ichiki \& Parish, 1972] or red blood cell [Pearson \& Raffel, 1971] antigens induce cell-

Report of a WHO Scientific Group

593

mediated immunity whereas unmodified antigens induce antibody formation. These modified antigens may have determinants that are poorly recognized by B cells but are still able to stimulate T cells. Alternatively, the effective dose of a given determinant may be reduced by these modifications. Early studies have in fact shown that minute doses of certain antigens [Salvin, 1958], particularly when complexed with antibody in appropriate proportions, can evoke cell-mediated immune responses, (b) Another possible explanation is that the surfaces of infected macrophages or other cells present antigen to T cells in a highly stimulatory form.

Further information concerning the conditions required to induce cell-mediated immunity would be particularly helpful for the prophylaxis and treatment of human disease. It could permit, for example, the production of safer, non-viable vaccines for smallpox and some other virus diseases, tuberculosis, brucellosis, Chagas' disease, and many other infections of man and domestic animals. It might also lead to more effective and rationally based immunotherapy in human cancer.

We turn now to the cellular basis of the cell-mediated immune response. There is clear experimental evidence from studies on laboratory rodents that the specific effector cells of this response arise directly from the antigen-driven proliferative response of progenitors that are members of a recirculating pool of T cells. This evidence is briefly summarized below. Thymocytes bearing isotopic [Joel et al., 1972], chromosomal [Dav-ies, 1969], or antigenic markers [Miller \& Sprent, 1971] have been shown to migrate to thymus-dependent areas of secondary lymphoid tissue (periarteriolar sheath of spleen and paracortical area of lymph nodes) [Parrott et al., 1966], and to appear in thoracic duct lymph. Procedures that deplete the recirculating pool of T cells, e.g., neonatal thymectomy [Miller \& Osoba, 1967], antilymphocyte serum (ALS) treatment [Me-dawar, 1969], or adult thymectomy followed by lethal irradiation and bone marrow reconstitution [Parrott et al., 1970], profoundly suppress cell-mediated immune responses. Proliferation of T cells occurs in the thymus-dependent areas of lymph nodes [Davies et al., 1969] and spleen during the induction of cell-mediated immunity, and stimuli that do not provoke a response in these areas fail to confer protective immunity to a variety of parasitic agents. The kinetics of this response will be discussed below. Progenitors of the specific effector cells of cell-mediated immunity appear to be present in the thymus, spleen, and the recirculating pool of lymphocytes [Sprent \& Miller, 1971; Cerottini et al, 191Q; Cooper \&

594 Cell-Mediated Immunity and Resistance to Infection

Ada, 1972; Blanden \& Langman, 1972] but seem to be scarce in bone marrow. A final indication is that antisera against markers of T lymphocytes eliminate specific effector cells from populations of immune lymphoid cells [Blanden \& Langman, 1972; Blanden, 1971; Lane \& Unanue, 1972].

Little is known about the life history of the progenitors of effector T cells. There is also scant information available regarding the requirement for cooperation among cell types in the induction of a cell-mediated immune response or the nature of such cooperating cells. However, on the basis of studies of graft-versus-host reactions in mice it has been proposed that induction can require cooperation between two different classes of T cell [Raff \& Cantor, 1971; Asofsky et al, 1971]. The two types may belong to different cell lineages or may represent different stages of maturation within a single cell line. The first type of $\mathrm{T}$ cell postulated $(\mathrm{Tt})$ is normally present 
in the thymus and spleen and may decrease in number in secondary lymphoid tissue 2-6 weeks after adult thymectomy, i.e., it might be in an early stage of post-thymic maturation in these tissues. The second type postulated (T2) is scarce in the thymus and does not decrease in number in secondary lymphoid tissue after adult thymectomy, i.e., it might be in a late stage of postthymic maturation. It has been suggested that Ti cells are the progenitors of effector cells and that $\mathrm{T} 2$ cells act as amplifiers of the response.

Thus far, investigations of the cellular requirements for cell-mediated immune responses in other systems [Sprent \& Miller, 1971; Cerottyni et al, 1970; Cooper \& Ada, 1972; Blanden \& Langman, unpublished observations] suggest that cooperation between $\mathrm{Tj}$ and $\mathrm{T} 2$ cells as defined above is not essential, and that $T$ cells at various stages of post-thymic life can act as progenitors of effector T cells. For example, mouse thymus cells transfered to lethally irradiated recipients can generate, within 1 week of antigenic stimulation, effector $T$ cells that mediate delayed hypersensitivity to bacterial antigens, kill tumour cells, or trigger skin graft rejection. Basically similar experiments have shown that $\mathrm{T}$ cells mediating antibacterial resistance can arise from progenitors that have resided for less than 3 weeks in secondary lymphoid tissues. These findings are compatible with the concept that Tx type cells act as progenitors but suggest that $\mathrm{T} 2$ amplifiers are not absolutely essential for the response. Mice thymectomized as adults at least 6 weeks before antigenic stimulation can produce an unimpaired cell-mediated immune response to bacterial infection; in such animals, cells of the Tt type would be absent.

Report of a WHO Scientific Group

595

This indicates that $\mathrm{T} 2$ cells can also act as progenitors of cells mediating antibacterial resistance, i.e., that they are not functionally restricted to amplifier activity.

The possibility that cooperation between $\mathrm{T}$ cells (defined as a single broad cell class) is a general phenomenon in cell-mediated immune responses cannot yet be excluded.

References

Asofsky, R., Cantor, H. \& Tigelaar, R. E. (1971) In: Amos, B. D. (ed.), Progress in Immunology, New York \& London, p. 369

Blanden, R. V. (1971) J. exp. Med., 133, 1974

Blanden, R. V. \& Langman, R. E. (1972) Scand. J. Immunol., 1, 379

Cerottini, J.-C, Nordin, A. A. \& Brunner, K. T. (1970) Nature (Lond.), 227, 72

Cooper, M. G. \& Ada, G. L. (1972) Scand. J. Immunol., 1, 247

Davies, A. J. S. (1969) Transplant Rev., 1, 43

Davies, A. J. S., Carter, R. L., Leuchars, E. \& Wallis, V. (1969) Immunology, 17, 111

Ichki, A. T. \& Parish, C. R. (1972) Cell. Immunol., 4, 264

Joel, D. D., Hess, M. W. \& Cottier, H. (1972) J. exp. Med., 135, 907

Lane, F. C. \& Unanue, E. R. (1972) J. exp. Med., 135, 1104

Medawar, P. B. (1969) Proc. roy. Soc. B, 174, 155

Miller, J. F. A. P. \& Osoba, D. (1967) Physiol. Rev., 47, 437

Miller, J. F. A. P. \& Sprent, J. (1971) Nature [new Biol.], 230, 267

Parish, C. R. (1971) J. exp. Med., 134, 21

Parrott, D. M. V., de Sousa, M. A. B. \& East, J. (1966) J. exp. Med., 123, 191

Parrott, D. M. V. de Sousa, M. A. B., Fachet, J., Wallis, V., Leuchars, E. \& Davies, A. J. S.

(1970) Clin. exp. Immunol., 7, 387

Pearson, M. N. \& Raffel, S. (1971) J. exp. Med., 133, 494 
Raff, M. C. \& Cantor, H. (1971) In: Amos, B. D. (ed.), Progress in Immunology, New York \& London, Academic Press, p. S3

Salvin, S. B. (1958) J. exp. Med., 107, 109

Sprent, J. \& Miller, J. F. A. P. (1971) Nature [new Biol.], 234, 195

2.2 Cells Involved in the Expression of Cell-Mediated Immunity

\subsubsection{Specific Effector Cells}

Techniques permitting the enumeration of individual antibody-secreting cells have

revolutionized cellular immunology and enabled detailed studies to be made of the kinetics of the production of these cells in the course of immune responses. There is a great need to develop similar

596 Cell-Mediated Immunity and Resistance to Infection

techniques for the detection of individual antigen-specific effector T cells, obviously a much more difficult task than the detection of cells secreting specific antibody. One such method currently being developed is described elsewhere in this report (see page 55).

In vitro and in vivo studies of the specific effector cells of cell-mediated immunity are based on various functions of these cells that can be measured quantitatively. These include the cooperative 'helper' function in antibody synthesis; transformation to blast cells; release of mediator substances that activate macrophages; direct target-cell killing; adoptive transfer of immunity to infections, grafts, and tumours; and immunologi-cal memory. It is not known whether the same $\mathrm{T}$ cell can participate in all these functions or whether different $\mathrm{T}$ cell populations are involved. Since the nature and specificity of individual $\mathrm{T}$ cells in the population have not yet been determined, considerable caution is required in interpreting the available studies of the histogenesis of cell-mediated immune responses to infective agents and the biological functions of effector cell populations, discussed below.

As already mentioned, organisms that can survive and multiply intra-cellularly are known for their ability to induce a cell-mediated response. The magnitude and kinetics of the response are influenced by several factors, e.g., the dose and virulence of the parasite and possibly the number of effective antigenic determinants involved. The best studied examples are the responses to Mycobacterium tuberculosis and Listeria monocyto-genes in mice and rats, which have been investigated with two basic techniques, (a) In mice, the histological changes and dividing cell populations in responding spleen or lymph nodes have been followed in relation to the course of infection, (b) In rats, cells harvested at different times from thoracic duct lymph of infected donors have been transferred to syngeneic recipients where their antibacterial effects and physiological properties have been studied.

The general picture emerging from these studies is as follows. Dividing cells appear in the thymus-dependent areas of lymphoid tissues within 1-2 days after infection. In the spleen, dividing cells are subsequently seen to increase in number in the red pulp. The peak of the response depends on the type of infective agent and the dose employed. With Listeria in the mouse, the peak occurs at 6 days [North, 1972]; with tubercle bacilli, it occurs later [North et al., 1972]. In the early phases the dividing cells are large blasts with pyroninophilic cytoplasm, but in later phases many of them have the appearance of pyroninophilic small lymphocytes.

Report of a WHO Scientific Group

597

In mice infected with virulent tubercle bacilli, the dividing cells in the spleen have a generation time of about $11 \mathrm{~h}$. Three or four divisions occur before the progeny leave the spleen and enter the blood. These data are in good agreement with the findings in other bacterial and viral 
infections, and with the results obtained in a system involving a response to allogeneic cells, in which sensitized lymphocytes were detected by various means within 3-6 days of stimulation. After their generation in lymphoid tissue, specific effector lymphocytes enter the bloodstream and localize at sites of infection in other tissues. Cells generated in the spleen can enter the blood directly, whereas those generated in lymph nodes must first traverse efferent lymphatics and the main lymphatic ducts. Lymphocytes with the ability to protect normal recipients appear in the thoracic duct within $72 \mathrm{~h}$ of a primary listeriosis in rats. The level of resistance transferred by a standard number of lymphocytes increases to a peak on day 6 and then declines rapidly. In contrast, protective cells formed in response to BCG appear later and can be demonstrated in the lymph for at least several months. Studies using the antimitotic drug vinblastine suggest that it is the dividing cells that are responsible for transferring resistance to Lister ia, in view of the finding that a single injection of the drug can eliminate protective lymphocytes from an actively immunized donor. There is also evidence indicating that non-dividing lymphocytes perform effector functions in vitro and possibly in vivo. Protective lymphocytes from BCG-injected donors are resistant to vinblastine, provided the cells are obtained late in the infection. An effective defence against intracellular parasites requires a mechanism for generating and accumulating sensitized lymphozytes and nonspecific effector cells, such as mononuclear phagocytes, in foci of infection. Sensitized lymphocytes, when stimulated by antigen, may serve to recruit nonspecific effector cells to such foci. This recruitment mechanism appears to be important in mousepox, for example, in which the virus, growing in hepatic parenchyma cells, produces lesions devoid of infiltrating cells until the animal becomes immune [Blanden, 1971]. In this case, the recognition of antigen by sensitized lymphocytes in the blood would seem to be the event initiating cellular infiltration. Other examples are the rapid initiation of the rejection process in a completely healed, unin-flamed skin graft after the injection of specifically sensitized cells, and the specific localization of labelled, specifically cytotoxic T cells at site of implantation of allogeneic tumours. On the other hand, studies using radio-labelled thoracic duct cells have shown that dividing lymphocytes, regard-

598

Cell-Mediated Immunity and Resistance to Infection less of their immunological specificity, are arrested at sites of inflammation [Koster \& McGregor, 1971]. This points to a mechanism by which inflammation, initiated either nonspecifically or by specifically sensitized lymphocytes, could be amplified in the infected host. 2.2.2 Nonspecific Effector Cells

Since there is no evidence that specifically sensitized lymphocytes are themselves able to kill micro-organisms, the collaboration of ancillary effector cells is most likely required for resistance to infection. The nature of this collaboration is discussed in the next section (2.3.1). The principal collaborating cell appears to be a mononuclear phagocyte. The term 'mononuclear phagocyte system' has been proposed for macrophages, monocytes, and their precursor cells [van Furth et al., 1972]. These originate from stem cells in the bone marrow that continuously multiply and differentiate to become promonocytes, which are phagocytic and adherent to glass. Promonocytes then divide and differentiate into monocytes, which are released into the circulating blood. Blood monocytes enter the tissues and differentiate into macrophages having an increased phagocytic capacity and lysosome content. Tissue macrophages include Kupffer cells of the liver, free and fixed macrophages of the spleen, lymph nodes, and bone marrow, alveolar macrophages of the lung, macrophages of other tissues, and perhaps also osteoclasts of 
bone and microglia cells of the central nervous system. (Reticulum cells and endothelial cells are excluded from this category.)

Mononuclear phagocytes are distinguished by their nuclei, their phagocytic capacity, the nature and content of their lysosomes (which differ from those of poylmorphonuclear leucocytes), their adherence to glass and other surfaces, and the presence on their plasma membrane of receptors for certain immunoglobulins or immune complexes (IgGl, IgG3, and IgM) and complement (C3).

Normally, tissue macrophages turn over continuously and slowly and divide infrequently. Under pathological conditions macrophages in inflammatory lesions arise mainly from blood monocytes, although local multiplication of macrophages may also occur. Cytokinetic studies do not support the view that mononuclear phagocytes are derived from lymphocytes.

The main physiological function of macrophages is to rid the blood, lymph, and tissues of particles, including micro-organisms and effete cells. This elimination process can be considered to take place in three

Report of a WHO Scientific Group

599

stages: attachment of the particles to the plasma membrane of macrophages, phagocytosis, and discharge of lysosomal enzymes into the phago-cytic vesicles containing the particles. The attachment of particles to the plasma membrane is often facilitated by antibody, especially in the presence of complement, or by other as yet unidentified constituents of normal serum collectively termed opsonins. Some kinds of particle may become attached without apparent need for serum factors. Phagocytosis probably results from plasma membrane reactions triggering the contraction of an actomyosin contractile microfilament system, with consequent infolding of the plasma membrane to which the particles are attached. Usually phagocytosis is followed by the fusion of lysosomes with the phagocytic vacuole containing the particle, but sometimes (e.g., after ingestion of live M. tuberculosis or Toxoplasma organisms) this fusion is inhibited. Whether this explains persistent infection in these cells is not yet known.

The bulk of particles or other materials ingested by macrophages is rapidly broken down in the lysosomal system. Some particles, however, undergo slow digestion or remain undigested. In the case of most antigens associated with macrophages, about $10-20 \%$ of the antigen is broken down slowly and retains immunogenicity for many hours at least. Also in this category are materials that cannot be degraded, for example, pneu-mococcus polysaccharide, cell wall constituents of certain organisms (including group A streptococci and mycobacteria), and inorganic particles such as carbon or silica. Part of the still undigested antigen remains on the surface of the cells and may be involved in stimulating both humoral and cell-mediated immune responses.

The mechanisms by which micro-organisms are killed in macrophages are poorly understood. Certain organisms can survive and multiply within the macrophages of normal animals, and thus give rise to many of the infections discussed in this report. Some also appear to be able to multiply in macrophages taken from immune animals, e.g., leishmaniae (section 3.5).

Unlike polymorphonuclear leucocytes, macrophages retain considerable synthetic potential and can be stimulated to form large amounts of lysosomal and other enzymes. Such stimulation or activation can be brought about in several ways, with a variety of end results. Macrophages cultured in the presence of anticellular antibody, streptococcal cell walls, or other stimulants have a greatly increased content of lysosomal enzymes. In comparison with normal macrophages, macrophages recovered 
600 Cell-Mediated Immunity and Resistance to Infection

Table I. Distinguishing characteristics of T lymphocytes, B lymphocytes, and macrophages Membrane markers T lympho- B lympho- Macro-

cytes cytes phages

$\mathrm{IgG}+$

Receptor for C3 (erythrocyte - antibody -

complement [EAC] rosettes) - $+\quad+$

Receptor for Ig or Ab-Ag complexes $(\mathrm{Fc}) \quad-$

Thymus-specific antigens $(\beta$, mouse thymocyte

leukaemia antigen, etc. $)+\quad-\quad-$

Receptors for sheep red blood cells

(erythrocyte [E] rosettes)

in vitro stimulation of DNA synthesis by mitogensa

Phytohaemagglutinin (PHA)

Concanavalin A (Con A)

Lipopolysaccharide (bacterial endotoxin)c

Anti-Ig Specific binding to antigen-coated beads Mixed lymphocyte culture reactivity Graftversus-host reaction inducing capacity Adherence to surfaces (glass, plastic) Phagocytic

a These data derive mainly from experiments in mice, and their extrapolation to man is questionable.

b Some B lymphocytes may be recruited to divide secondarily by factors elaborated by activated $\mathrm{T}$ lymphocytes. B cells may also be stimulated when the mitogen is attached to a solid support.

c In mice.

d Except for blast cells.

e Except for mature plasma cells or when immune complexes are attached to B cells.

from animals infected with organisms that can multiply within cells show increased spreading on glass, elevated lysosomal hydrolase levels, a higher percentage of glucose metabolism by the hexose monophosphate pathway as compared with the glycolytic pathway, and increased capacity to kill or inhibit the replication of a variety of organisms. These changes are not necessarily causally related. The terms 'stimulated' or 'activated' must not be used loosely but should always be defined in terms of the agent utilized to produce the effect and the method by which the effect is

Report of a WHO Scientific Group

601

assayed. Evidence that the increased microbicidal capacity of macrophages is related to specific cell-mediated immunity is discussed in section 3.1.1.

The properties of macrophages, T cells, and B cells are summarized in table I.

References Blanden, R. V. (1971) J. exp. Med., 133, 1090

FURTH, R. VAN, COHN, Z. A., HIRSCH, J. G., HUMPHREY, J. C., SPECTOR, W. G. \&

Langevoort, H. L. (1972) Bull. Wld Hlth Org., 46, 845 Koster, F. T. \& McGregor, D. D. (1971)

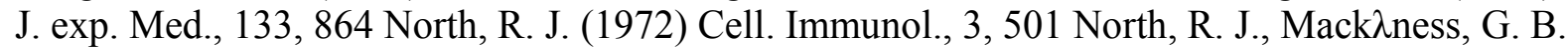
and Elliot, R. W. (1972) Cell. Immunol., 4, 680

2.3 Expression of Cell-Mediated Immunity

2.3.1 Cell Collaboration

The transfer of immune lymphoid cells to syngeneic recipients in models of bacterial and viral infection has demonstrated that the expression of cell-mediated immunity involves collaboration 
between specifically sensitized $\mathrm{T}$ cells and nonspecific inflammatory cells. The most important ancillary cell seems to be the mononuclear phagocyte (macrophage), although the roles of other cell types have yet to be fully elucidated. Evidence for the participation of macrophages in the regression of foci of infection includes the following findings:

(1) Ionizing irradiation and cyclophosphamide interrupt monocyte production by inactivating the precursors of these cells in bone marrow. As a result there are few circulating monocytes, and under these condi tions an injection of immune spleen cells containing specifically sensitized T cells fails to provide full protection against infections [Tripathy \& Mackaness, 1969; Blanden, 1971; McGregor \& Koster, 1971].

An injection of normal bone marrow restores the capacity of irradiated animals to express immunity conferred by immune cell transfer [Hahn \& Mackaness, unpublished observations]. When monocyte precursors are labelled by injections of tritiated thymidine, labelled monocytes can be seen to enter foci of infection from the bloodstream much more rapidly in specifically sensitized animals than in normal subjects [Mackaness \& North, unpublished observations].

602 Cell-Mediated Immunity and Resistance to Infection

The sequence of events involving collaboration between $\mathrm{T}$ cells and macrophages is thought to be as follows. Specifically sensitized T cells recognize antigens in foci of infection, with recognition possibly occurring in the lesion or at the surface of blood vessels adjacent to the foci (in liver sinusoids, for example). The sensitized T cells then trigger or increase the influx of inflammatory cells, both polymorphonuclear and mononuclear. This recruitment probably depends upon the production by $\mathrm{T}$ cells of im-munologically nonspecific factors (see section 2.3) that attract or arrest bloodborne polymorphonuclear and mononuclear phagocytes. Poly-morphs may not persist in a focus. However, they are sometimes prominent in incipient lesions and their influence on the fate of the parasite is worthy of further investigation, even though mononuclear cells constitute the majority of cells in mature lesions. Within the focus, it seems likely that macrophage activation occurs in response to the local production of chemical mediators (which are attributable, directly or indirectly, to sensitized T cells). It thus appears that the collaboration between $T$ cells and macrophages operates on two levels: T cells attract or arrest blood monocytes, thus promoting their accumulation in foci of infection, and there influence their metabolic state to produce activated macrophages.

The relative importance of these two mechanisms depends on the infective agent. In mousepox (ectromelia virus infection) the triggering of an influx of inflammatory cells into sites of infection appears to be the more important effect. In several bacterial infections that have been studied in detail and in infections caused by a number of other agents, the activation of macrophages is probably of primary importance. A broader appraisal of these mechanisms will be given in subsequent sections.

\subsubsection{Molecular Mediators}

Some of the phenomena associated with the expression of cell-mediated immunity can be simulated in appropriate test systems by certain products of sensitized lymphoid cells cultured in vitro with specific antigens. The best characterized and most widely studied product of antigenstimulated lymphoid cells is, of course, immunoglobulin antibody. In recent years, however, a number of factors that differ physicochemically from immunoglobulins and that produce their effects independently of the continued presence of antigen (i.e., nonspecifically in immunological terms) have been clearly implicated in the expression of cell-mediated immune 
reactions. These products have been grouped under a variety of generic terms, such as products of activated lymphocytes (PALs), lymphocyte ac-

Report of a WHO Scientific Group

603

tivation products (LAPs), lymphokines, and chemical mediators of cellular immunity. Although produced in minute quantities, these factors can exert profound biological effects in vitro and in vivo and may prove to be of considerable importance to basic and clinical immunology. At the molecular level they may provide insight into the qualitative basis of cell-mediated immune reactions. At the clinical level, where there is an urgent need for in vitro diagnostic tests to measure cell-mediated immunity in general or immunity to specific antigens, these factors may serve as useful diagnostic indicators. There are also reports indicating that some factors in the supernatants from antigen-stimulated lymphocytes show immuno-logical specificity; in addition, some phenomena reportedly have been reproduced by the use of macrophages passively carrying antibodies (termed cytophilic antibodies) that give them a specific affinity for antigen. As a whole, these findings may point to the existence of a variety of effector and amplifying mechanisms for the expression of cell-mediated immunity. However, the major factors with biological activity are those produced by sensitized lymphocytes upon stimulation in vitro with specific antigens, as described in table II. It should be noted that interferon can also be produced by other cells in other circumstances.

(1) Products of Activated Lymphocytes

One or more of the various active factors listed in table II can be produced by cells of hypersensitive donors stimulated in vitro with (a) bacterial antigens, such as PPD, streptolysin O (STO), streptokinase-streptodornase (SKSD), Candida protein antigen, or lepromin; (b) purified protein antigens and synthetic polypeptides; (c) hapten-protein conjugates; (d) certain skinreactive carbohydrate antigens; (e) viruses such as influenza and mumps; (f) transplantation alloantigens in the mouse and guineapig; and (g) tumour-specific transplantation antigens. In addition, migration inhibition factor (MIF) and interferon have been found to be produced after $72 \mathrm{~h}$ of mixed lymphocyte cultures. Mitogens such as phy-tohaemagglutinin (PHA) and concanavalin A (Con A) have been shown to induce the production of relatively large amounts of MIF and lympho-toxin (LT). It is possible that permanent lymphoblastoid cell lines may also produce such factors. Production of these factors is inhibited by agents that block protein synthesis.

In general, the presence of a small number of macrophages is required for the production of mediators by antigen-stimulated cells, as in the case of blast cell transformation. The macrophages may act by presenting anti-

604 Cell-Mediated Immunity and Resistance to Infection

Table II. Biological activities of products of activated lymphocytes

A. Affecting macrophages

Migration inhibition factor (MIF)

Macrophage aggregation factor (MAF)

Macrophage chemotactic factor (MCF)

Macrophage resistance factor (postulated)

cytophilic antibodies

inhibits the migration of normal

macrophages agglutinates macrophages in

suspension causes macrophages to migrate 
through micropore filter along

gradient renders macrophages nonspecifically

resistant to infection with certain

bacteria and viruses confer on macrophages specific

reactivity with antigen

B. Affecting lymphocytes

Blastogenic or mitogenic factor (BF or MF)

(PF)

Potentiating factor

Cell cooperation or helper factor Suppressor factor (postulated)

C. Affecting granulocytes Inhibition factor

Chemotactic factor

induces blast cell transformation and tritiated thymidine incorporation in normal lymphocytes augments or enhances ongoing transformation in mixed lymphocyte culture or antigen-

stimulated cultures

produced by $\mathrm{T}$ cells, increases the number or rate of formation of Ab-producing cells in vitro

inhibits activation of, and/or antibody production by, B cells

inhibits the migration of human buffy coat cells or peripheral blood leucocytes from capillary

tubes or wells in agar plates

causes granulocytes to migrate through micropore filter along a gradient

D. Affecting cultured cells Lymphotoxin

Proliferation inhibition factor

and cloning inhibition factor Interferon

(LT) cytotoxic for certain cultured cells,

e.g., mouse L cells or HeLa cells

(PIF, CLIF) inhibit proliferation of cultured cells without lysing them protects cells against virus infection

Report of a WHO Scientific Group 605

Table II (continued)

E. Producing effects in vivo

Skin reactive factor (possibly (SRF) in normal guineapig skin induces

a combination of several of the indurated skin reactions that are

above activities) histologically similar to delayed-

type hypersensitivity reactions

Macrophage disappearance factor injected intraperitoneally, causes

macrophages to adhere to peritoneal wall

gen in an effective way, or they may have a feeder function. While production of mediators and blast cell transformation often occur concomi-tantly, there is strong evidence that under certain circumstances the two phenomena may be dissociated. MIF production can be stimulated by certain tubercle bacillus carbohydrates or tobacco mosaic virus proteins in the absence of blast cell transformation; conversely, blast transformation without MIF production has been observed in lymphocytes from patients with chronic mucocutaneous candidiasis.

In intact animals immunization schedules that usually lead to the appearance of cell-mediated immunity can produce cytophilic antibodies. 
(2) Physicochemical Nature

None of the antigen-independent factors has been purified and characterized in definitive chemical terms, but it is clear that they are not immu-noglobulin molecules. In the guineapig, MIF is a glycoprotein with a molecular weight range of 35,000-65,000, as determined by calibrated Sephadex columns; LT is associated with molecules of 80,00-150,000. Lymphocyteproduced interferon seems to have a molecular weight of approximately 20,000. While it seems unlikely that each biological activity studied will be found to be mediated by a separate chemical entity, it is not known which activities are performed by the same molecule.

The immunologically specific factors produced by stimulated lymphocytes in vitro have not been characterized or distinguished from antibodies. In the sera of actively immunized animals, however, macrophage cytophilic antibodies have been found in some subclasses of IgG (IgGl and IgG3 in man; IgG2 in guineapigs and mice) and in IgM (in man and mouse). In addition, there is some evidence for the existence, in mice, of

606 Cell-Mediated Immunity and Resistance to Infection cytophilic activity in IgA antibodies and in an 'antibody' with fast $\alpha$-glob-ulin electrophoretic mobility. Antibodies cytophilic for B lymphocytes also exist. It must be borne in mind that antibodies may also be cytotropic for granulocytes (IgGl in man) and mast cells (IgE in man).

(3) Evaluation of Molecular Mediators

The existence of the various factors described above suggests a simple qualitative interpretation of the events that may occur in certain cell-mediated immune reactions. According to this interpretation, sensitized lymphocytes circulate and become stimulated to synthesize biologically active products when they interact with specific antigen in the tissues. The chemotactic factor might be responsible for the accumulation of mono-cytes and macrophages at sites of antigen implantation; the blastogenic factor might activate adjacent lymphocytes in the tissue, i.e., act as an amplification mechanism for the few sensitized cells at the site; the migration inhibition factor might arrest macrophages at the site of the reaction; and the postulated macrophage resistance factor might account for the increased nonspecific resistance to infection of macrophages, although for this effect cell-cell interactions might be required. Infected or otherwise antigenically altered cells might be destroyed or limited in their growth by lymphotoxin and the proliferation inhibition factors; and uninfected cells might be protected from viral infection by interferon. This interpretation is of course highly speculative and has yet to be tested in vivo. Nevertheless, it serves to emphasize two phases in the cell-mediated immune response: a specific recognition of antigen by lymphocytes and their production of biologically active factors, followed by a nonspecific phase in which these products act on a variety of other target cells. The exception to this general rule is cytophilic antibody. It is possible that a major biological role of cytophilic antibodies is to confer upon macrophages specific cytotoxic reactivity for nucleated cells, in addition to their obvious role as efficient opsonins.

Despite the attractiveness of this scheme, a number of problems remain to be solved. (1) Although there is abundant evidence that cell-mediated immune phenomena in vivo are thymusdependent, there is little firm experimental proof that any of the mediators is produced solely by T cells. This question is currently under intensive investigation. (2) The degree of heterogeneity of sensitized lymphocytes with respect to effector function is unclear; for example, it is not known whether every factor can be produced by every stimulated lymphocyte or whether some factors are

Report of a WHO Scientific Group

607 
produced only by a subpopulation. (3) The assays for the production of these factors were developed in experimental animal models. Before they can be applied to man, they will need to be made more sensitive and considerably more refined so that they can be used as standard tests of immu-nological function in human disease. In addition the extent to which the significance of the findings in experimental animals can be extrapolated to man must be tested by appropriately controlled studies in man. (4) The specificity of some of the factors needs further investigation. For example, lymphotoxin exhibits little specificity in its cytotoxic effects in vitro, whereas the destruction of allogeneic target cells by sensitized lymphocytes is exquisitely specific. (5) There must be better chemical purification, chemical characterization, and discrimination among the individual factors. (6) Finally, there is an urgent need to define the conditions under which sensitized lymphocytes reacting with antigen induce macrophage activation leading to nonspecific resistance to infective agents.

2.3.3 Direct Attack

If the antigen inducing the immune response is a normal or abnormal constituent of a cell membrane (histocompatibility antigen, tumour antigen, viral antigen, autoantigen), sensitized lymphocytes may exert a direct cytotoxic effect on the target cell carrying the sensitizing antigen(s). This effect can be assayed quantitatively in vitro and has been extensively studied in allograft and tumour systems [Perlmann \& Holm, 1969]. It has also been shown that target cells containing growing viruses and having viral antigens on their surfaces are recognized and destroyed by sensitized lymphocytes in vitro [Speil et ah, 1968]. The destruction of host cells harbouring slowly multiplying or oncogenic viruses could be of considerable importance in the host-virus relationship. (In no case has there been a demonstration of a direct killing of protozoa or bacteria by sensitized lymphocytes.) The biochemical mechanism of target cell destruction by lymphoid cells is still unknown. It is independent of complement and requires direct contact between reacting cells. While in most allograft systems target cell destruction in vitro has been shown to be mediated by sensitized T cells (see 1 below), several additional mechanisms of in vitro target-cell killing by other types of cell have been described and should be taken into consideration. The latter mechanisms are described under 2-4 below.

(1) Direct cytotoxicity of sensitized T cells. In allograft systems, the thymic origin of the cytotoxic lymphocytes has been demonstrated by

608 Cell-Mediated Immunity and Resistance to Infection

showing that (a) cytotoxic lymphocytes are formed after the transfer of thymus cells into lethally irradiated allogeneic mice and in mixed thymus cell cultures in vitro; (b) cytotoxic lymphocytes carry $\mathrm{T}$ cell surface markers such as theta and mouse thymus lymphocyte antigen (MTLA); and (c) anti-Ig antisera do not inhibit their cytotoxicity. The immunological specificity of target cell destruction has been confirmed by the inhibitory effect of antisera to target cell antigens and by the lack of killing of anti-genically unrelated innocent bystander cells [Brunner \& Cerottyni, 1971].

Antibody-dependent cell-mediated cytotoxicity. In some in vitro systems, cells from normal lymphoid tissue have been shown to destroy target cells to which antibody is attached [Perlmann \& Holm, 1969; McLennan, 1972]. The reaction is independent of complement, dependent on $\mathrm{IgG}$, and mediated by cells possessing receptors for Fc. It is inhibited by anti-Ig antisera and by immune complexes. The effector cell has not been definitely identified, but possible candidates are B cells, macro-phages, granulocytes, and A cells [Allison, 1972]. No in vivo phenomena corresponding to this in vitro model have thus far been described. 
Cytotoxicity of 'specifically armed' macrophages. Peritoneal (adherent) macrophages of mice immunized with allografts or syngeneic tumour cells have been shown in some systems to be specifically cytotoxic after the removal of non-adherent cells [Alexander et ah, 1972]. Cytotoxicity has also been conferred on normal macrophages following incubation with noncytotoxic spleen cells from recipients of syngeneic tumour grafts. Finally, a cytotoxic effect has been observed in normal macrophages incubated with supernatants from interactions between immune lymphoid cells and target cells. It seems possible that in some of these systems adherent T lymphocytes, B lymphocytes, A cells, or cytophilic antibody may have been involved. Cytotoxicity of activated macrophages. Peritoneal macrophages from animals infected with intracellular organisms display nonspecific increased microbicidal activity. They have also in some systems been shown to be nonspecifically toxic for certain target cells [Hibbs et al,, 1972]. In particular, cells with abnormal growth characteristics were sensitive to the cytotoxic effect, but embryonic fibroblasts were not. The formation of nonspecifically cytotoxic macrophages may also be induced by several injections of live BCG into mice.

The significance of cytotoxic mechanisms 2-4 for in vivo immune responses is not clear.

Experiments based on adoptive immunization of

Report of a WHO Scientific Group

609

immunosuppressed animals have shown that immunity to histoincompatible (allogeneic) tumours can be passively transferred with pure suspensions of sensitized T cells into lethally irradiated and/or silica-treated mice [Freedman et al., 1972], while immunity to syngeneic tumours carrying tumour-specific antigens can be transferred only to unirradiated mice or to irradiated (700 R) bone-marrow reconstituted mice [Zarling \& Tev-ethia, 1972]. These experiments suggest that in allograft systems T cells alone may suffice for target cell killing, while in tumourspecific systems host macrophages or other cells of bone-marrow origin may act as nonspecific effectors of cell-mediated immunity. This possibility should be investigated more thoroughly. References Alexander, P., Evans, R. \& Grant, C. K. (1972) Ann. Inst. Pasteur, 122, 645 Allison, A. C. (1972) Ann. Inst. Pasteur, 122, 619 Blanden, R. V. (1971) J. exp. Med., 133, 1074

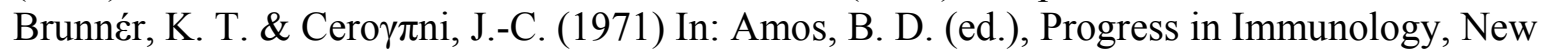
York \& London, Academic Press, p. 386 Freedman, L. R., Cerot $\pi$ ni, J.-C. \& Brunner, K. T. (1972) J. Immunol., 109, 1371 Hybbs, J. B., Lambert, L. H. \& Remington, J. S. (1972) Nature [new Biol.], 235, 48 McGregor, D. D. \& Koster, F. T. (1971) Cell. Immunol., 2, 317 McLennan, I. C. M. (1972) In: Thymus Dependency, New York, Plenum Press

(In press) Perlmann, P. \& Holm, G. (1969) Adv. Immunol., 11, 117 Speil, L. F., Osborn, J. E. \& Walker, D. L. (1968) J. Immunol., 101, 409 Tr $\pi>$ athy, S. P. \& Mackaness, G. B. (1969) J. exp. Med., 139, 17 Zarlyng, J. M. \& Tevéthia, S. S. (1973) J. nat. Cancer Inst. (In press)

2.4 Interactions between Antibody-Mediated and Cell-Mediated Immunity

In most immune responses it is accepted that there is some degree of B cell stimulation as well as $\mathrm{T}$ cell stimulation. B cell involvement in what is operationally a $\mathrm{T}$ cell effector mechanism may vary from system to system and may result in increased reactivity, suppressed reactivity, or qualitatively altered reactivity. Interaction can occur in the induction phase and/or at the effector level. For example, B cells may inhibit T cell effec-

610 Cell-Mediated Immunity and Resistance to Infection 
tor action, as in contact sensitivity or Jones-Mote hypersensitivity, in which case the selective depletion of B cells from lymphoid tissue by cyclophosphamide before sensitization can result in an effective increase in $T$ cell function. The increased resistance to Listeria following pretreatment of mice with cyclophosphamide and the increased resistance to tumour growth following pretreatment with antisera against plasma cells are probably related phenomena. In contrast, under certain experimental conditions humoral antibodies potentiate $\mathrm{T}$ cell effects. The selective depletion of B cells before immunization, for example, results in a decrease of T cell effects, e.g., delayed-type skin reactions.

2.4.1 'Immunological Enhancement'

The phenomenon of so-called 'immunological enhancement' was first described in connexion with tumour allografts in mice but has now been demonstrated in skin and renal allograft systems. Tumour allografts in contact with non-cytotoxic specific antisera show 'enhanced' growth and are protected from the cytotoxic immunological reactions of the host directed against them. Antibody, for example, can react with antigen in the tumour to protect it from cellmediated immune lysis. It has also been postulated that the antibody covering the antigenic determinants on the tumour prevents it from eliciting a cell-mediated immune response. Antibody might therefore inhibit cell-mediated immunity at either the afferent or the efferent level, or both. Immunological enhancement can be produced not only passively by the injection of antibody but actively by preimmunization of the recipient with tumour extract or with specific transplantation antigens.

Immunological tolerance has been attributed to a specific deletion or inactivation of sensitized lymphocytes specific for the antigen involved. However, in recent experiments it has been observed that animals rendered tolerant to allogeneic cells have specific factors in their sera that can block lymphocyte-mediated cytotoxicity in vitro. It is not yet known whether these blocking factors are humoral antibodies or antigen-antibody complexes. The role of these factors in vivo and particularly in infectious diseases remains to be determined.

In view of the high level of circulating mycobacterial antibodies in patients with lepromatous leprosy, it has been suggested that immunological enhancement may contribute significantly to the state of specific cell-mediated immune unresponsiveness that is characteristics of this disease. However, there is not yet any direct evidence for its involvement.

Report of a WHO Scientific Group

611

\subsubsection{Immune Deviation}

Under certain circumstances a specific unresponsiveness of cell-mediated immunity and Ig2 antibody production can be produced in the guineapig by preimmunizing the animal with alumprecipitated antigen followed by antigen in a form that should normally induce cell-mediated immunity. Alum-precipitated bovine immunoglobulin injected up to 14 days previously will prevent an animal from responding with a cell-mediated immune response (delayed hypersensitivity) when immunized with the same antigen in complete Freund's adjuvant. Similarly, immunization of guineapigs with tuberculin-PPD subcutaneously three times 4-5 weeks before sensitization with BCG vaccine or with alum-precipitated PPD 1-2 weeks before BCG sensitization reduces this eventual tuberculin responsiveness. Although the serum from these animals does not contain antibody that would block sensitization in other animals, lymphocyte suspensions (containing presumably both B and T lymphocytes) are relatively ineffective in transferring delayed hypersensitivity. Hence, in immune deviation prior B cell sensitization and production of antibodies may inhibit the subsequent development of $\mathrm{T}$ cell 
reactivity. The failure to demonstrate humoral antibody does not exclude the possibility of interaction between B and T cells in immune deviation, as in Jones-Mote sensitivity (see below).

2.4.3 Jones-Mote Form of Delayed Hypersensitivity

Delayed hypersensitivity reactions that differ from classical tuberculin hypersensitivity may occur in animals sensitized with trace amounts of serum proteins and mycobacterium-free adjuvants. They are distinguished from classical delayed hypersensitivity reactions by (a) their earlier appearance, i.e., after 12-24 h, and (b) their failure to persist beyond 14 days after the sensitizing stimulus, i.e., at the time when tuberculin hypersensitivity is just beginning to be fully established. These reactions have been called 'Jones-Mote' reactions after the authors who first described them in man. Recently it has been said that they differ histologically from normal tuberculin-type hypersensitivity in that the cellular infiltrate in the dermis contains a large number of basophils. This has led to the coining of the term, 'cutaneous basophil hypersensitivity'. Similar numbers of basophils appear to be present in the infiltrate in chemicalcontact sensitivity. However, the studies of Jones-Mote reactions give little indication as to their mechanism or how they differ functionally from tuberculin hypersensitivity. An increase in circulating basophils is a feature sometimes as-

612 Cell-Mediated Immunity and Resistance to Infection

sociated with the production of antibody to serum protein antigens. Thus, one might suspect that an increase in these cells in delayed-type skin lesions might indicate an interaction between antibody and sensitized lymphocytes. In recent studies it has been possible to inhibit antibody production in experimental animals by pretreatment with a large dose of cyclophos-phamide before sensitization, which selectively depletes B lymphocytes while leaving $\mathrm{T}$ cell function relatively unimpaired. Under these conditions the development of a cell-mediated immune response in the draining lymph node is unaffected. However, after such treatment animals sensitized so that they would normally produce Jones-Mote reactions instead produce reactions of the tuberculin type, and those sensitized by epicuta-neous painting in contact sensitivity produce more intense reactions, which sometimes persist up to 8 days after skin testing. These findings might mean that, in the case of Jones-Mote hypersensitivity and chemical-contact sensitivity, B lymphocyte function (possibly antibody) is modulating $T$ cell function and that the modified skin reactions observed result from the interaction between these two functions. In classical tuberculin-type hypersensitivity, the modulating function of B cells would appear to play little part in the final manifestation of the reaction, perhaps because $T$ cells are sensitized to such a greater extent than B cells. As a result, tuberculin-type reactions are not increased in intensity by cy-clophosphamide but are decreased, possibly as a result of the drug's suppression of other antibodies that normally augment $\mathrm{T}$ cell function.

2.4.4 T Lymphocyte Modulation of B Lymphocyte Function It has been known for some time that antibody responses to many antigens, including proteins, are facilitated by $\mathrm{T}$ cells acting as 'helpers' or amplifiers of the B cell response. This phenomenon has been termed 'cell cooperation'. Although B cells can produce a weak IgM response to most antigens, the conversion from IgM to IgG production appears to require the participation of activated $\mathrm{T}$ cells. $\mathrm{T}$ lymphocytes may be stimulated in their helper functions by determinants of the specific antigen, by adjuvants, or by allogeneic lymphoid cells.

Recent evidence suggests that $\mathrm{T}$ lymphocytes can also act in the opposite fashion, exerting a regulatory or 'suppressor' effect on B cell function. This may explain certain states of immunological tolerance in which (1) normal lymphoid cells are unable to confer responsiveness 
upon syn-geneic immunologically tolerant recipients; and (b) lymphoid cells, probably T cells, from immunologically tolerant animals can transfer tolerance

Report of a WHO Scientific Group

613

to normal syngeneic recipients. It is not known whether the 'suppressor' T cells block antibody formation by acting directly on the B lymphocytes or by acting on the 'helper' T cells. The relationship between helper $\mathrm{T}$ lymphocytes, suppressor $\mathrm{T}$ lymphocytes, and the $\mathrm{T}$ cell involved in cell-mediated immunity requires more detailed investigation. Conceivably, some instances of specific immune unresponsiveness in infectious diseases (section 4.2) may be related to suppressor T cells.

3. Characteristics of Cell-Mediated Resistance to Various Types of Infection

3.1 Bacterial Infections

\subsubsection{Macrophage Activation}

The biological properties of pathogenic bacteria are extremely varied, and the devices used by the host in self-defence are equally complex. Some potentially pathogenic agents can be controlled merely by an immune response yielding antitoxic or opsonic antibodies that can neutralize a toxic product or facilitate phagocytosis. Bacteria that are readily killed by phagocytic cells (e.g., Streptococcus pneumoniae, Haemophilus influ-enzae) are easily disposed of in this way. However, humoral mechanisms of acquired immunity, although important, lie outside the scope of the present section, which concerns bacteria that can survive and multiply within phagocytes and the operation of cell-mediated immunity $\mathrm{m}$ resisting them.

The first advance made in analysing the mechanism of resistance to organisms of this sort was the discovery that macrophages obtained from tuberculous rabbits and guineapigs differ markedly from those of normal animals. The findings of recent years have shown that these altered macrophages, which possess enhanced nonspecific microbicidal activity, are produced by specific immunological processes; and that immunity sometimes depends upon this activated condition of the host's phagocytic cells.

The workings of this mechanism of resistance are most easily studied with organisms that multiply in the macrophages of non-immune subjects but are killed in the activated macrophages of immune animals. L. mono-cytogenes infection of mice [Mackaness, 1962] has been a most valuable model because listeriosis is an acute infection to which immunity, when it develops, is very powerful, and because investigation has been facilitated

614 Cell-Mediated Immunity and Resistance to Infection

by the development of inbred strains of mice and of markers to distinguish between $\mathrm{T}$ and $\mathrm{B}$ cells. Using this experimental model it has been found that resistance develops in step with the formation of macrophages that can ingest and kill listeriae in vitro, and that macrophages with this property appear in parallel with the development of delayed hypersensi-tivity to listeria antigens. Antibody from convalescent mice is unable to protect normal recipients, but lymphocytes from a peritoneal exudate, the spleen or the thoracic duct of actively infected mice confer both delayed-type hypersensitivity and specific immunity to L. monocytogenes [Mackaness, 1969]. The active cells in the population have been identified as T cells.

If specifically sensitized lymphocytes are transferred to a normal animal and the recipient is not challenged, the recipient's macrophages remain normal. However, if specific antigen is injected, e.g., as in a test for hypersensitivity, or if the recipient receives a specific challenge infection, its macrophages become activated within $24 \mathrm{~h}$. The microbicidal properties of the stimulated cells 
from such animals, like those obtained during infection, are nonspecifically enhanced because they depend upon metabolic changes. Two microbicidal mechanisms appear together in the activated macrophage: one that is common to normal and activated macrophages, and another that is blocked by metabolic inhibitors which interfere with the microbicidal activity of polymorphonuclear phagocytes but not of normal macrophages.

All of the criteria customarily used to distinguish between cell- and antibody-mediated mechanisms of immunity indicate that macrophage activation is a manifestation of cell-mediated immunity and results from the interaction of (microbial) antigens with specifically sensitized lymphocytes. This effect has been reproduced in an in vitro model [Simon \& Sheagren, 1971]. 3.1.2 Importance and Limitations of Macrophage Activation It should not be assumed that the activation of macrophages is the only or even the most important effect that specifically sensitized lymphocytes can exert on host macrophages. Both the fixed and the free macrophages of animals that have been specifically sensitized by cell transfer can synthesize DNA and divide when the recipient is injected with specific antigen or challenged with the homologous infective agent. In addition, the monocytes of the challenged animals can be shown by appropriate labelling techniques to leave the blood and enter hepatic and pulmonary

Report of a WHO Scientific Group

615

listerial lesions in larger numbers than in non-sensitized animals [Macka-ness \& North, unpublished observations]. This presumably reflects their recruitment into lesions by sensitized lymphocytes.

The rapid accumulation of macrophages at foci of infection provides the hypersensitive animal with a local defence that is effective against parasites that are easily killed by mononuclear phagocytes. However, for parasites that are not easily killed (e.g., L. monocytogenes, Brucella abortus, Salmonella typhi) the mere assembling of macrophages at a focus of infection may not suffice to suppress the infective agent. Under such circumstances macrophage activation is an important extra step toward the development of host resistance. However, even fully activated macrophages may not be potent enough to deal with exceptionally hardy parasites, which can resist their antimicrobial mechanisms (e.g., M. tuberculosis). When this happens, the parasite tends to persist as a source of anti-genic stimulation, the influx of phagocytic cells continues, and granuloma formation results.

The significance of granuloma formation is discussed in section 4.3, but it is worth noting here that the walling off of foci of infection and the combined influence of the many active cells aggregated within a tubercle, for example, may affect the ability of parasites to survive and multiply. The triad of chronicity, delayed-type hypersensitivity, and granuloma formation thus becomes a characteristic feature of infections in which cell-mediated immunity has a role to play in the host-parasite relationship. Indeed, a delayed hypersensitivity reaction in the skin is simply an elicited illustration of what is taking place at foci of infection throughout the tissues.

On the basis of these features, it is reasonable to suggest that cell-mediated immunity may participate in the host-parasite relationship in the following diseases: tuberculosis, brucellosis, glanders, typhoid (carrier state), tularaemia, syphilis, leprosy, melioidosis, and lymphogranuloma venereum. It should be noted, however, that none of these characteristic features proves that the role of cell-mediated immunity in host resistance is an important one. For example, delayed-type hypersensitivity to SKSD develops following infection with S. pyogenes, but immunity to this organism is undoubtedly dependent upon antibody. The same may be true of infection with Staphylococcus aureus, to which a very high percentage of human subjects show delayed-type 
hypersensitivity. It is possible, however, that the pathogenesis of staphylococcal infections and their tendency to become chronic may be rooted in the effects of cell-mediated hypersen616 Cell-Mediated Immunity and Resistance to Infection

sitivity. Chronic granulomatous disease of childhood (CGD) is interesting in this connexion. This disease is associated with a defect in granulocyte function, as a result of which the subject responds abnormally to catalase-positive bacteria, and the cellular composition of his tissue reaction to them resembles delayed-type hypersensitivity reactions. It is not known whether cellmediated immunity is called upon as a second line of defence in CGD, but it would be interesting to determine whether delayed hypersensitivity develops toward antigens of infective agents such as Serratia marcescens, which is so frequently found in the lesions of CGD.

References

Mackaness, G. B. (1962) J. exp. Med., 116, 381 Mackaness, G. B. (1969) J. exp. Med., 129, 973 Simon, H. B. \& Sheagren, J. N. (1971) J. exp. Med., 133, 1377

3.2 Virus Infections

It is essential to make a distinction between mechanisms bringing about recovery from a primary virus infection and those conferring protection against reinfection. For example, antibody may not be produced early enough to be present in effective amounts during the period critical for recovery from primary infection but may subsequently reach levels that confer complete protection against reinfection. Antibody acts mainly by neutralizing virus at the portal of entry (e.g., IgA on mucous membranes) or in the blood, thus preventing bloodborne infection of target organs. Antibody may also promote an accumulation of nonspecific effector cells in foci of infection in solid tissues in a manner similar to cell-mediated immunity. While it is generally accepted that antibody plays a major role in preventing reinfection, there is little information concerning the role of cell-mediated immunity in resistance to reinfection, largely because immunized animals invariably possess both antibody-mediated and cell-mediated immunity, and the importance of each is difficult to appraise separately. This section is mainly concerned with the role of cell-mediated immunity in recovery from primary acute virus infections. Among other important problems outside the scope of this discussion are the failure of immune mechanisms in most persistent virus infections, certain immunopathological aspects of virus infections recently considered

Report of a WHO Scientific Group

617

by WHO1, and the role of cell-mediated immunity in limiting virus onco-genesis.

The following general statement can be made concerning the relationship between virus infection and cell-mediated immunity. As a rule, viruses that bud from the surface membranes of infected cells or that cause incorporation of virus-specified antigens in infected cell surfaces are those that induce cell-mediated immunity. Obviously, the development of cell-mediated immunity to such viral antigens does not necessarily imply that this type of immunity contributes significantly to recovery or resistance. The mode of replication and spread of the virus appears to be an important factor in determining the relative importance of cell-mediated and humoral immunity in recovery from virus infections. Antibody cannot enter cells and neutralize intracellular virus. Herpesvirus can spread directly from cell to cell in the presence of antibody, so that neutralization of virus in infected tissues is inefficient. Antibody does not neutralize measles virus replicating in the form of incomplete nucleocapsids without envelope antigens in the central nervous system. 
There is now good evidence pointing to the importance of cell-mediated immunity in recovery from infections by herpesvirus, poxvirus, and measles virus. Mice that have been neonatally thymectomized or treated with ALS and infected parenterally with herpes simplex virus as adults, frequently develop lethal infections. Another example that has been studied in detail is the mechanism of recovery from ectromelia virus infection (mousepox), which may provide a model for smallpox in man. Mice infected with a virulent strain of this virus and treated with ALS rapidly die of progressive liver necrosis. Antibody and interferon levels are not affected by ALS treatment but cell-mediated immunity is markedly impaired. The transfer of immune syngeneic lymphoid cells has provided evidence in support of the view that cell-mediated immunity is a major factor in recovery. It seems that this type of immune response acts primarily by inducing the accumulation of inflammatory cells in foci of infection, since in the absence of immune mechanisms the virus continues to grow in and destroy hepatic parenchyma cells while inflammatory infiltration of the necrotic tissue fails to occur.

Specifically sensitzed $\mathrm{T}$ cells act to recruit inflammatory cells to foci of infection; mononuclear phagocytes in the inflammatory infiltrate then appear to engulf and destroy the infective virus.

Since $\mathrm{T}$ cells have not yet

* Bull. Wld Hlth Org., 47: 257 (1972).

618 Cell-Mediated Immunity and Resistance to Infection

been demonstrated to secrete significant amounts of antibody, the principal mechanism involved is probably the production of immunologically nonspecific factors that attract or arrest bloodborne polymorphonuclear and mononuclear phagocytes. A role of special classes of antibody in the later development of mousepox lesions cannot be excluded with certainty. Polymorphs after their entry into the focus appear to have a short life-span, but they constitute a large proportion of the cells in incipient lesions and their role in the subsequent development of antiviral mechanisms deserves investigation.

Mononuclear cells, including macrophages, constitute the majority of cells in mature lesions. Quantitative studies indicate that macrophage populations infected with ectromelia virus in vivo produce fewer infectious progeny after one virus growth cycle than were ingested at the initiation of the cycle. Hence, the phagocytosis of infective virus by macrophages in a lesion would eventually eliminate the infection. The activation of macrophages (as manifested by an increased ability to kill listeriae), which has now been demonstrated to occur in ectromelia and lymphocytic choriomeningitis infections of mice, could increase the cells' viricidal activity in sites of infection.

Two other mechanisms by which cell-mediated immunity might control virus infections have also been examined. First, specifically sensitized T cells have been shown to establish contact with and kill virus-infected cells in vitro, presumably because of virus-specified antigens on the surfaces of the infected cells. While this mechanism is obviously significant in infections caused by oncogenic and non-cytolytic viruses, its importance in cytolytic infections is difficult to assess. To cause a reduction in the growth rate of virus in infected tissues, the killing of infected cells would need to occur before the completion of intracellular maturation of progeny virions. Second, the action of antigen on specifically sensitized cell populations also triggers the production of interferon, which, together with locally produced antibody, could augment the antiviral effect of macrophages in foci of infection and protect other cells.

These observations suggesting an important role for cell-mediated immunity in promoting recovery from certain virus infections in experimental animals are consistent with clinical experience in man (table III). Patients with uncomplicated severe hypogammaglobulinaemia 
recover normally from vaccination against smallpox as well as from measles and varicella infections. However, in congenital abnormalities with prominently defective cell-mediated immunity, including ataxia-telangiectasia,

Report of a WHO Scientific Group 619

Table III. Virus infections of severity increased in human patients with different types of immunodeficiency*

Immunodeficiency Virus infection

aggravated

Hypogammaglobulinaemia paralytic poliomyelitis

with intact cell-mediated

immunity

Deficient cell-mediated vaccinia

immunity ( \pm normal herpes simplex

immunoglobulins) herpes zoster

varicella

cytomegalovirus infection measles

a For references see: Allison, A. C. (1973) Ann. Inst. Pasteur, 123, 585.

Swiss-type agammaglobulinaemia, and the syndromes of Wiskott-Aldrich, Gitlin, Nezelof, and

Di George, virus infections are a recurring and often fatal complication. Progressive vaccinia has been described in patients with many of these syndromes, especially Nezelof's syndrome, in which immunoglobulin levels and specific antibody-synthesizing capacity are near normal. Patients with the Wiskott-Aldrich syndrome are particularly susceptible to infection with cytomegalovirus, measles virus and especially herpes simplex virus. Patients with cartilage-hair hypoplasia, which is associated with a defect of cell-mediated immunity but normal antibody levels, develop unusually severe varicella infections. Cancer chemotherapy, immunosuppressive therapy after renal homografting, Hodgkin's disease, and some other debilitating diseases, all of which depress cell-mediated immunity more profoundly than humoral immunity, increase the patient's susceptibility to infections, particularly by cytomegalovirus, herpes simplex virus, and herpes zoster (varicella) virus.

However, even when cell-mediated immune responses are manifested against viral antigens, it does not necessarily mean that they are important in recovery. The evidence available suggests that in many primary virus infections, e.g., those caused by enteroviruses and togaviruses (arthropod-transmitted viruses), a major role in recovery is played by circulating antibody. Experimental animals can be made susceptible to lethal infec-

620 Cell-Mediated Immunity and Resistance to Infection

tions by these viruses if they are immunosuppressed, e.g., by cyclophos-phamide, and this susceptibility can be reversed by the administration of antiviral antibody after the infection is well established. Children with severe hypogammaglobulinaemia uncomplicated by defects of cell-mediated immunity are considerably more susceptible to paralytic poliomyelitis, even with vaccine strains of virus, whereas experimental animals that have been neonatally thymectomized or treated with ALS do not show undue sensitivity to these infections. Neonatally thymectomized chickens recover normally from influenza virus infections while bursectomized chickens develop more severe disease. These findings, and other observations on passive protection, suggest that cell-mediated immunity is less important than humoral immunity in promoting recovery from avian influenza virus infection. In infections of seromucous surfaces (the respiratory, 
gastrointestinal, and urinary tracts), a protective role has been attributed to locally secreted antibody, notably of the IgA class, particularly against reinfection.

3.3 Mycoplasma Infections

The relative roles of circulating antibodies, locally secreted antibodies, and cell-mediated immune mechanisms in mycoplasma infections are not known. In man and hamsters, the level of protection against Mycoplasma pneumoniae correlates poorly with circulating antibody titres.

Guineapigs infected with M. pneumoniae show delayed hypersensitivity when inoculated with killed organisms, and their lymphocytes, as well as those of convalescent human subjects, can be stimulated in vitro by M. pneumoniae antigens. Mice that have been thymectomized or Xirradiated and treated with ALS are more readily infected with M. pulmonis than normal mice, and the spread of organisms from the lungs to other parts of the body, such as the brain, occurs more frequently in immunosuppressed mice. While the lungs of infected mice with intact immune systems show marked peribronchiolar and perivascular cuffing by mononuclear cells, these phenomena are much less prominent in immunosuppressed animals. These results suggest that cell-mediated immunity plays a role in immuno-pathological reactions in the lungs of animals infected with Mycoplasma, perhaps by increasing the microbicidal activity of alveolar macrophages, which prevent the organisms from spreading to other parts of the body. Macrophages in culture rapidly engulf opsonified mycoplasmas and digest them. The role of cell-mediated immune mechanisms and their interac-

Report of a WHO Scientific Group

621

tions with humoral immunity in local and systemic mycoplasma infections deserve further investigation.

3.4 Fungus Infections

The existence of cell-mediated immunity to fungus infection in man is suggested mainly by the association of certain fungal agents with specific clinical situations:

Neonatal deficiency of thymus function is often associated with mucocutaneous candidiasis. Hodgkin's disease may be complicated particularly by cryptococcal meningitis.

The administration of corticosteroids or cytotoxic drugs often predisposes the patient to infection with opportunistic fungi (e.g., Aspergil-lus, Candida, Mucor).

Treatment with corticosteroids or cytotoxic drugs may exacerbate latent fungus infections (e.g., histoplasmosis, coccidioidomycosis, blasto-mycosis).

Disseminated infection with certain fungi (e.g., Coccidioides, His-toplasma, Plastomyces) is usually associated with high antibody titres but absent delayed hypersensitivity to the corresponding fungal skin test antigen, whereas in localized infection with these fungi delayed hypersensitivity is present and there may be no demonstrable antibody or only low titres.

Antifungal therapy in patients with the disseminated infection may result in the appearance or return of delayed hypersensitivity.

In mucocutaneous candidiasis, delayed skin hypersensitivity to Candida antigens is frequently impaired but humoral antibodies to candidae are demonstrable by precipitation or agglutination. In patients with negative Candida skin tests, the results of in vitro testing varies from one case to the next: (a) lymphocytes may transform upon exposure to Candida antigens but not produce MIF; or (b) both lymphocyte transformation and MIF production may be absent. In the relatively small number of cases studied thus far, no consistent correlation has been found between in vitro testing with Candida antigens and delayed skin hypersensitivity to the same antigen preparations. 
Immunotherapeutic measures (lymphocyte transfer or administration of transfer factor) have resulted in the development of delayed skin test reactivity to candidae, antigen-specific lymphocyte transformation, and

622 Cell-Mediated Immunity and Resistance to Infection

MIF production, and in some cases have led to remarkable clinical improvement of the mucocutaneous lesions.

An association between cryptococcal meningitis and Hodgkin's disease was noted even before the availability of corticosteroids and cytotoxic drugs. Hodgkin's disease is associated with a generalized failure of cell-mediated immunity, and experimental data suggest that cell-mediated immunity is involved in resistance to Cryptococcus. In experimental models in vitro, and in laboratory animals in vivo, activated macrophages have a far greater capacity to kill this fungus than normal macrophages. Human monocytes show a significant capacity for killing cryptococci in vitro.

Systemic candidiasis is an increasingly frequent cause of morbidity and mortality in patients severely compromised by underlying disease and/or therapy. It has been demonstrated that a major role in the killing of can-didae is played by the polymorphonuclear leucocyte, and an important feature prerequisite for this is the integrity of the myeloperoxidase system. Although less efficient, human monocytes also kill candidae. Under experimental conditions, it has been shown that these organisms are actively phagocytosed by and multiply in mouse macrophages. Virulent species rapidly produce filaments that rupture and kill the cells. Activated macrophages show no resistance to Candida albicans although they are normally capable of eliminating cryptococci.

Coccidioidomycosis and the resultant delayed hypersensitivity to coc-cidioidin occur in a large percentage of the population in well-defined local endemic areas. Lymphocytes from patients with strongly positive delayed skin hypersensitivity to coccidioidin are specifically stimulated in vitro by this antigen, whereas lymphocytes from patients with negative skin tests are unresponsive. There is also a good correlation between skin-test responsiveness to coccidioidin and lymphocyte transformation induced by coccidioidin.

In humans, the results of histoplasmin skin tests and in vitro histoplas-min-induced lymphocyte transformation show good agreement. However, a consistent correlation between complementfixing or precipitating antibody titres in autologous serum and transformation levels cannot be demonstrated.

Delayed hypersensitivity is also seen in other fungus infections in man. At present, however, the role of cell-mediated immunity to these fungi, as well as most of those mentioned above, is poorly defined. Further studies on fungus infections in neonatally thymectomized or ALS-treated animals and transfers of immune lymphocytes or serum are indicated.

Report of a WHO Scientific Group

623

3.5 Protozoal Infections

The major genera of protozoa responsible for serious diseases in man are Plasmodium, Trypanosoma, and Leishmania. Protozal diseases are dissimilar in nature, even in some cases when the causal organisms belong to the same genus. The evidence for acquired resistance in man also varies in quantity and quality with the disease, and adequate animal models are not always available. Clinical and experimental evidence bearing on the role of cell-mediated immunity in resistance to particular protozoal infections is considered below. Both in man and in 
experimental animals, the analysis of mechanisms of resistance is often complicated by the occurrence of antigenic variation in the parasites.

The acquisition of resistance to malaria in man has been inferred from such observations as the relative resistance to reinfection (and lower levels of parasitaemia) of long-term residents of endemic areas as compared with previously unexposed individuals, and their relative lack of clinical signs and symptoms despite persistent parasitaemia. Infection may be followed by the production of humoral antibodies. There is also evidence that cell-mediated immune responses occur. Peripheral blood lymphocytes of patients partially immune to infection with P. falciparum were found to transform into blast cells when incubated with extracts of $P$. falciparum gametocytes or trophozoites, whereas lymphocytes from uninfect-ed persons did not. The ability to transform persisted for as long as 2 years after radical cure. Chronic infection is associated with gross hyperplasia of the mononuclear phagocytic system. In infected patients, splenectomy is followed by a marked increase in blood parasite levels, but the immu-nological basis (if any) of this effect is not known. An important role for humoral antibodies in resistance to human malaria parasites is suggested by the beneficial effects of the transfusion of antibody-containing serum to infected patients.

A partial picture of the mechanisms that may be involved has emerged from studies P. knowlesi infections in monkeys and P. berghei infections in rodents. The adverse effects on resistance of neonatal thymecto-my in rats and hamsters and of ALS treatment in rats strongly imply that $T$ cells play an important role, in which their function as helper cells in antibody production appears to be only partly involved. Transfer studies indicate that antibody-containing serum can confer some resistance on normal animals. More effective transfers of resistance have been achieved by the use of immune spleen cells. Species-specific resistance to P. know-

624 Cell-Mediated Immunity and Resistance to Infection

lesi has been induced in monkeys by immunization with killed trophozoites in complete Freund's adjuvant but not with killed trophozoites in incomplete Freund's adjuvant. The former procedure leads to the development of specific cell-mediated immunity and some activation of macrophages, whereas both procedures promote general antibody production. Mice immunized with irradiated sporozoites are found to develop resistance, whereas mice immunized with dead sporozoites do not; this is perhaps analogous to the known superiority of live over dead vaccines in inducing resistance to certain bacterial infections (section 2.1).

There is evidence that macrophages become activated in the course of experimental malaria infections, at least to the extent that their capacity to phagocytose parasitized erythrocytes is increased. Macrophages activated as a result of BCG infection show a similar increase in phagocytic capacity. Phagocytosis appears, however, to require the presence of specific antibody. Some resistance to malaria has been induced in mice by the injection of Corynebacterium parvum, which is known to cause ma-crophage activation but which is also an adjuvant. A combined mechanism of resistance has been proposed in which macrophages activated as a result of a cell-mediated immune reaction presumably act synergistically with antibodies. It should be mentioned, however, that there is some experimental evidence for the existence of a class of antibodies that can, as in other systems, inhibit the operation of protective immune mechanisms.

In the various forms of human trypanosomiasis there appears to be no evidence for or against the existence of cell-mediated immune responses. Histological studies of the brains of some patients who died of African trypanosomiasis revealed lesions resembling those of experimental allergic encephalomyelitis, which, in animals immunized with myelin antigens, may be due to cell- 
mediated immunity. It is not know whether these lesions resulted from cell-mediated allergic reactions to trypanosome antigens or from cell-mediated autoimmunity triggered in some way by the infection.

Arthus-type (antibody-mediated) hypersensitivity reactions to parasite antigens have been demonstrated in Trypanosoma congolense infected rabbits. This parasitic infection is primarily intravascular, whereas T. brucei organisms may be found in blood, lymph, cerebrospinal fluid, and organs, especially the brain. Skin tests and macrophage migration inhibition tests have not revealed cell-mediated responses to trypanosome antigens prepared from the infecting $\mathrm{T}$. congolense strain or from substrains.

Animals infected with T. brucei or T. rhodesiense exhibit both Arthus

Report of a WHO Scientific Group

625

and delayed-type hypersensitivity. The delayed hypersensitivity does not occur in animals inoculated with dead parasites. Transfer of delayed hypersensitivity has been accomplished with live spleen cells.

In patients with chronic Chagas' disease due to T. cruzí, it has been possible to demonstrate delayed-type hypersensitivity (skin reactions) to crude trypanosomal antigen preparations. Whether the cell-mediated immune response provides a measure of immunity and whether conversion to the acute form of the disease with cardiomyopathy is associated with a failure of cell-mediated immunity are questions that merit serious attention. In animal models of this infection there is some evidence that cell-mediated immunity may play a role in resistance. Attempts to transfer immunity with serum have been unsuccessful or equivocal. However, preliminary experiments indicate that the transfer of putatively immune lymphoid cells may confer some resistance. Neonatal thymectomy or X-irradiation exacerbates the disease and increases mortality.

Further investigations are required to establish whether or not there is an association between cell-mediated immunity and resistance to trypano-somes in general, and in each particular disease.

Organisms of the genus Leishmania cause a variety of clinical manifestations in man. (a) Cutaneous leishmaniasis of the Old World is generally self-healing and is accompanied by some antibody formation (this occurs only rarely) and by cell-mediated immunity (delayed-type hypersensitivity). (b) Diffuse cutaneous leishmaniasis, a persistent infection with apparently the same organism, is accompanied by neither significant antibody formation nor delayed-type hypersensitivity. (c) Visceral leishmaniasis, if untreated, has a high mortality rate and is accompanied by antibody formation; only those patients who recover spontaneously or after treatment display delayed-type hypersensitivity. (d) The chronic form of mucocutaneous leishmaniasis of the New World (espundia) is accompanied by both antibody formation and delayed-type hypersensitivity. In all but the last form of leishmaniasis, therefore, there is a crude correlation between resistance and the occurrence of cell-mediated immunity.

Attempts have been made to analyse the immunological mechanisms of resistance to leishmaniasis using L. enrietti in guineapigs, an excellent model. This parasite inhabits guineapig macrophages and produces cutaneous infection, which is generally self-limiting. Recovery is accompanied by the development of delayed hypersensitivity. In immunosuppressed animals lesions can become disseminated, but recovery can occur despite the development of only minimal delayed-type hypersensitivity. In vitro

626 Cell-Mediated Immunity and Resistance to Infection 
studies on the possible mechanisms of parasite elimination have shown that macrophages from immune animals and macrophages that are activated (as indicated by their capacity to kill listeriae) do not destroy ingested leishmaniae. However, the inability of activated macrophages to kill the parasite under these in vitro experimental conditions does not necessarily imply that cell-mediated immunity is unimportant in resistance to Leishmania. It has been reported that cellmediated immunity may operate through a specific cytotoxic attack by sensitized lymphocytes upon parasitized macrophages. However, this finding has proved difficult to reproduce. Furthermore, the killing of host cells would not be an effective means of resistance unless the contained parasites were also destroyed. On the other hand, a possible role for antibody is suggested by experiments showing that leishmaniae treated with immune serum and complement do not survive when added to normal macrophage cultures. The biological significance of the in vitro experiments is thus not clear. Experiments involving transfers of immune serum and cells should provide important information, since L. enrietti infection in the guineapig may be a model in which cell-mediated immune responses occur but where the outcome is partly determined by the production of antibody.

L. tropica infection in mice serves as another model infection for the study of resistance to Leishmania. After primary infection with a limited number of organisms the local skin lesions can regress. A second infection causes lesions that develop more rapidly. The results of thymectomy suggest that cell-mediated immunity plays an important role in lesion development, and possibly also in regression.

Toxoplasma appears to infect man very commonly, but clinical manifestations of the infection are rare (except for congenital infections, disseminated infection in immunosuppressed patients, and ocular disease). Laboratory animals, especially mice, can become resistant to these parasites. There is strong evidence that activated macrophages are the nonspecific effectors of resistance to Toxoplasma in mice, although high-titred specific immune serum can confer some resistance on normal mice. Delayed hypersensitivity as elicited by the skin test, antigen-specific lymphocyte transformation, and inhibition of macrophage migration have been demonstrated during latent infection in man and laboratory animals.

It is necessary to conclude this section with a word of warning. Despite our lack of knowledge concerning the mechanisms of resistance to protozoa, it is clear that the administration of steroids and immunosuppressive drugs is often followed by exacerbation of chronic protozoal infections.

Report of a WHO Scientific Group

627

\subsection{Metazoal Infections}

The range of metazoal parasites causing disease in man and in domestic and experimental animals, and the clinical and pathological range of the diseases they cause, are even wider than the range of pathogenic bacteria and bacterial diseases. Two of the most important diseases caused by metazoa in man are schistosomiasis and hookworm infestation, which are among the most common serious diseases in the world.

Clinical and experimental observations on schistosomiasis suggest: (a) that immunologically mediated resistance occurs in man; (b) that the development and maintenance of resistance to further infection depend on the persistence of adult worms, a situation analogous to concomitant tumour immunity in tumour-bearing experimental animals; (c) that the target of the immune reactions involved in effective resistance is the schistoso-mula; and (d) that cell-mediated reactions to schistosome egg antigens cause allergic reactions that are part of the disease. It has 
also been postulated that resistance is cell-mediated, as little correlation has been observed in man between antibody levels and the apparent degree of resistance. Serum from experimentally infected monkeys has recently been shown to exert a toxic effect on young schistosomulae in vitro. However, the biological significance of this finding is not yet clear. The transfer of human serum with high antibody titres reportedly has no effect on established infections. The survival of adult parasites in the face of immuno-logical reactions may be due to their acquisition of host surface antigens.

Clinical observations also suggest that in hookworm infestations of man, the worm burden is controlled at a certain level by immunological reactions. Two experimental infections with gutdwelling nematodes have provided considerable insight into the mechanisms that may be involved in resistance: Nippostrongylus brasiliensis in rats and Trichostrongylus colubriformis in guineapigs. Upon exposure to antigens of the parasites, the animals show a full range of immune responses, from antibody production (including large amounts of homocytotropic antibody) to cell-mediated immunity. Expulsion of the worms may require several steps, including damage mediated by antibody, a lymphocyte-mediated reaction, and a step involving basophils, eosinophils, and vasoactive amines. The precise significance of each step, especially the lastmentioned, is currently under investigation. It is not clear exactly how lymphocytes contribute to worm expulsion in these infections. There does not yet appear to be adequate evidence to indicate whether they are B cells or T cells, which 628 Cell-Mediated Immunity and Resistance to Infection highlights the need to find convenient markers for these cells in animals other than mice. In another (and very different) experimental infection used as a model for filariasis, Litomosoides carinii in rats, the acquisition of resistance is marked by the adherence of lymphocytes and macrophages to microfilar-iae in the pleural cavity; this is apparently followed by destruction of the microfilariae. Although a major role by sensitized lymphocytes may well prove to be a common feature of resistance to metazoa, it seems fundamentally unlikely that such diverse organisms in diverse sites would be resisted by identical mechanisms.

4. Aberrant or Defective Functioning of Cell-Mediated Immunity

4.1 Nonspecific Unresponsiveness

Nonspecific unresponsiveness of $\mathrm{T}$ cell function to a variety of antigens can occur clinically as a result of what are known as primary immunodeficiency diseases. Nonspecific unresponsiveness in man can also be secondary to malnutrition, infection with micro-organisms, invasion by tumours, or treatment with X-rays or drugs that have a direct effect on immunological function. 4.1.1 Primary Immunodeficiency Diseases

The diseases affecting cell-mediated immunity are those in which there is a primary deficiency of $\mathrm{T}$ cell function occurring either independently or as a result of stem-cell deficiency. These include severe combined immunodeficiency (stem-cell) and thymic hypoplasia (Di George syndrome). 1 A number of these conditions are fatal within the first 6 months of life; the infants that die are infected with Pneumocystis carinii, Candida, measles virus, and herpes zoster (varicella) virus. However there may be variable deficiencies of $\mathrm{T}$ cells in early childhood that are not in themselves fatal but lead to low-grade infection with micro-organisms requiring cell-mediated immunity for their elimination.

\subsubsection{Malnutrition}

Malnutrition is probably a major cause of deficiency of cell-mediated immunity, not only in developing countries but also in urban areas of the

i Bull. Wld Hlth Org. 45:125 (1971). 


\section{Report of a WHO Scientific Group \\ 629}

more developed countries. Malnutrition may be either primary, e.g., due to a deficient intake of food, or secondary, e.g., due to infection. The most commonly incriminated infections in secondary malnutrition are those of the upper respiratory tract or the gut, which give rise to a sort of pathophysiological cycle. For example, measles has a special tendency to precipitate kwashiorkor, and children with kwashiorkor who subsequently contract measles develop a particularly severe and often lethal form of the disease. Kwashiorkor is associated with an impairment of the ability to mount cell-mediated immune responses, particularly tuberculin reactivity following BCG vaccination, and children dying of kwashiorkor have been found to have atrophy of the thymus and other lymphoid tissues. It is not known whether the loss of cellmediated immunity in protein-calorie malnutrition occurs early or late, and the role of chronic infection in exacerbating the loss also needs further investigation. WHO is currently studying this problem. 1

\subsubsection{Infections}

Nonspecific loss of cell-mediated immunity also occurs in infectious diseases independently of malnutrition. In animals, the loss of cell-mediated immunity in virus infections has been shown to be due to the direct cytotoxic effect of the virus on lymphoid tissue, e.g., Newcastle disease in chickens and rinderpest in cattle. This effect might contribute to the observed depression of cellmediated immunity in man following infection with measles virus. Other infections associated with loss of cell-mediated immunity are Mycobacterium lepraemurium in mice, where there is prolonged retention of skin allografts, and possibly Plasmodium bergheíi infection, where there is a shortening of the latency period for Moloney virus leukaemogenesis. Up to 50\% of patients with lepromatous leprosy may have a diminished ability to develop contact sensitivity. However, they can be sensitized to show delayed hypersensitivity to keyhole limpet hae-mocyanin, and they do not have an increased incidence of other infections.

Nonspecific deficiencies of cell-mediated immunity can also be detected in individuals infected with Treponema pallidum. Rabbits infected at birth with this organism develop runt disease and their spleens are depleted of lymphocytes. Similar changes are found in the spleens of infants with congenital syphilis. Patients with primary and secondary syphilis 1 Bull. Wld Hlth Org. 46: 537 (1972).

\section{0}

Cell-Mediated Immunity and Resistance to Infection have diminished lymphocyte transformation upon exposure to PHA. In secondary syphilis, factors may be present in the plasma that can suppress the PHA-induced transformation of lymphocytes from normal individuals.

The nonspecific depression of cell-mediated immunity in infections may thus result from structural changes in lymphoid tissue or from humoral factors suppressing lymphocyte function. 4.1.4 X-Rays, Cytotoxic Drugs, and Corticosteroids In experimental animals X-irridiation, cytotoxic drugs, and corticosteroids are effective against both $\mathrm{B}$ cell function and $\mathrm{T}$ cell function. In humans, treatment with cytotoxic drugs is frequently associated with a loss of delayed hypersensitivity and a suppression of antibody formation. Patients receiving X-irradiation or cytotoxic drugs are particularly susceptible to disseminated infection with gram-negative bacteria and opportunistic pathogens, such as Nocardia, Aspergillus, Candida, Pneumocystis carinii, cytomegalovirus, and herpes simplex and zoster (varicella) viruses. Renal transplant patients on long-term immunosuppressive therapy have been 
discovered to have an increased incidence of tumours of the re-ticuloendothelial system.

Corticosteroids, while they combat infection, mainly by suppressing the acute inflammatory response, also have a sup-pressive effect on delayed hypersensitivity, which is apparently due to their anti-inflammatory properties as well as to their direct action on lym-phoyctes. The administration of these drugs too is associated with an increased incidence of infection with the organisms mentioned above. Unfortunately, these three therapeutic modalities are frequently necessary in patients with serious underlying disease in whom resistance to infection is already impaired (e.g., leukaemia, vascular collagen diseases, terminal cancer, etc.), and in whom the cell-mediated immune response to infection is thereby compromised even further.

\subsubsection{Diseases of the Reticuloendothelial System}

(1) Humoral Immunity Defect

Chronic lymphoproliferative disorders (chronic lymphatic leukaemia, lymphosarcoma, myeloma, Waldenström's macroglobulinaemia). These diseases are associated with an absolute or functional hypogammaglob-ulinaemia and an impaired antibody response. Patients are generally infected with pyogenic (e.g., pneumococcal, staphylococcal) and certain gram-negative bacteria. Report of a WHO Scientific Group 631

Acute leukaemia. Here the defect is primarily a deficiency of mature circulating polymorphonuclear leucocytes (and thus an impairment of the acute inflammatory response), which predisposes patients to infection with gram-positive pyogenic and gram-negative bacteria.

(2) Cell-Mediated Immunity Defect

Hodgkiris disease. Untreated patients have long been known to have increased susceptibility to the tubercle bacillus, Brucella, Listeria, Crypto-coccus, and herpes zoster (varicella) virus, i.e., to obligate or facultative intracellular organisms. Resistance to these organisms, as mentioned above, depends mainly on cell-mediated immune responses, and these responses are characteristically deficient in Hodgkin's disease. Patients frequently fail to show delayed skin hypersensitivity to antigens to which they have been previously exposed, and also often fail to develop delayed hypersensitivity when exposed to new antigens. Antigen-specific and PHAinduced lymphocyte transformation may be deficient even in early stages of the disease. There may also be a prolonged skin-allograft rejection time.

Sarcoidosis. This disease is frequently associated with an absence of delayed skin hypersensitivity and with prolonged skin allograft survival. Patients may have either impaired lymphocyte transformation on exposure to specific antigens and PHA and/or defective MIF production. However, there is no apparent increase in the incidence of infection with facultative intracellular organisms.

4.2 Antigen-Specific Unresponsiveness

In a number of diseases caused by facultative or obligate intracellular organisms there is a spectrum of clinical conditions associated with variations in the patient's effective levels of cellmediated immunity but lacking obvious relationship to concurrent antibody response. The disease that best exemplifies this is leprosy, in which the spectrum ranges from the lepromatous form of the disease, associated with a specific failure of cell-mediated immunity to the tuberculoid form, in which specific cell-mediated immunity is prominent. Between these two poles lies an arbitrary part of the spectrum known as 'borderline' leprosy. Patients in this part of the spectrum have clinical features that may vary from month to month depending on the extent to which they can mount a cell-mediated immune

632

Cell-Mediated Immunity and Resistance to Infection 
response against the invading organism. A rapid increase in cell-mediated immunity, pushing the disease from the lepromatous towards the tubercu-îoid pole of the spectrum, is often referred to as a 'reversal reaction', whereas a rapid loss of cell-mediated immunity pushing it from the tuber-culoid toward the lepromatous pole is called a 'downgrading' reaction. Throughout the spectrum there is an inverse relationship between the extent of lymphocytic infiltration in the skin and the bacterial load within the macrophages. This spectrum is mirrored by the reactivity of peripheral lymphocytes in vitro to antigens derived from M. leprae, as shown in experiments involving lymphocyte transformation.

A number of possible causes can be postulated for the defect of cell-mediated immunity in lepromatous leprosy. The development of lepromatous leprosy may depend on a host-determined characteristic present in a fixed proportion of the population, since the incidence of this form of the disease in a population does not drop in parallel with a reduction in the overall incidence of leprosy. A disease resembling lepromatous leprosy can be produced in mice whose $\mathrm{T}$ lymphocyte function has been blocked by adolescent thymectomy followed by $900 \mathrm{R}$ irradiation and bone marrow cell reconstitution. Such mice can be induced to develop borderline lesions by the transfer of normal $\mathrm{T}$ cells. However, there is considerable evidence in man that lepromatous leprosy develops from an antigen-specific defect in cell-mediated immunity, not from a nonspecific failure of $\mathrm{T}$ cell function. Another characteristic is that in patients with polar lepromatous leprosy the $\mathrm{T}$ cell defect is permanent and does not recover during antimycobacterial therapy. These patients have high levels of circulating antibodies to mycobacteria and are liable to develop immune-complex disease during chemotherapy, when soluble antigen is released and complexes are demonstrable in serum [Moran et ah, 1972]. Under these conditions effective cellmediated immunity could be blocked by mechanisms analogous to immunological enhancement or immune deviation (see section 2.4). However, although a nonspecific depressor has been detected in the serum of some lepromatous patients, pooled lepromatous serum has failed to inhibit M. Zeproe-antigen-induced transformation of lymphocytes from patients with the tuberculoid form of the disease [GoDALeía/., 1972]. Hence it is still uncertain in these patients whether antigen-specific T cells have been eliminated or inactivated. In patients with lepromatous leprosy nearer the borderline part of the spectrum, reducing the bacterial load can result in the reappearance of cell-mediated immunity.

Similar immunological mechanisms can be found in leishmaniasis, Report of a WHO Scientific Group

633

where the visceral form of the disease is associated with the absence of demonstrable specific delayed hypersensitivity and the presence of circulating antibody. Comparable mechanisms also seem to exist in histoplas-mosis, coccidioidomycosis, blastomycosis, primary and secondary syphilis, widely disseminated tuberculosis, and possibly brucellosis.

Mice congenitally infected with lymphocytic choriomeningitis (LCM) virus become lifelong carriers of high titres of virus. Some antibody is formed in the carriers against virus-specific antigens, leading to the gradual accumulation of antigen-antibody complexes in renal glomeruli. However, cell-mediated immunity to viral antigens, as judged by delayed hypersensitivity testing, is not demonstrable in the carriers. The transfer of lymphoid cells from LCM-immune syngeneic donors to carriers causes them to produce high levels of antibody. The results of treating the lymphoid cells with antisera to thymus-specific antigen suggest that the carrier $\mathrm{T}$ cells do not react to viral antigens and that immune $\mathrm{T}$ cells from the donors cooperate with $\mathrm{B}$ cells in the recipients to produce antiviral antibody. In other words, in congenital carriers the $\mathrm{T}$ 
cells but not the B cells show specific unresponsiveness to virus-specified antigens. Analogous mechanisms are thought to prevent autoimmune reactions to auto-antigens present in small amounts, such as thyroglobulin, and may also be operative in some other congenital infections. However, infections even in early fetal life often elicit vigorous immune responses.

References

Godal, T., Myrvang, B., Frøland, S. S., Shao, J. \& Melaku, G. (1972) Scand. J. Immunol., 1, 311 Moran, C. J., Ryder, G., Turk, J. L. \& Waters, M. F. R. (1972) Lancet, ii, 572 4.3 Granuloma Formation

For the purposes of the present report a granuloma is defined as a collection of inflammatory cells in which macrophages predominate. Granulomas may be induced by non-immunological or immunological means. Non-immunological granulomas are caused by the deposition of materials such as silica, colloidal aluminium hydroxide, or incomplete Freund's adjuvant (water-in-oil emulsion) in the tissues, or by the accu-

634 Cell-Mediated Immunity and Resistance to Infection

mulation of macrophages containing organisms that cannot be eliminated, such as M. leprae in lepromatous leprosy.

Immunologically induced granulomas results from the chronic accumulation of immune complexes in antibody excess, or from a chronic local cell-mediated immune reaction, such as that occurring around a schisto-some egg. The formation of granulomas due to cell-mediated immune processes is inhibited in animals by neonatal thymectomy or treatment with ALS, and can be accelerated by the transfer of specifically sensitized lymphocytes. Granuloma formation of this type may be responsible for pipe-stem fibrosis of the liver in schistosomiasis as well as for pulmonary fibrosis in tuberculosis.

5. Cell-Mediated Immunity in Clinical Diagnosis and Treatment 5.1 Diagnostic Measures Based on Cell-Mediated Immune Reactions

Tests of cell-mediated immunity, at the most fundamental level, can serve to establish whether an individual lacks specific reactivity to a particular antigen or whether he has a generalized inability to express cell-mediated reactivity to a variety of antigens. At a more sophisticated level, it would be desirable to have suitable tests for analysing the functional activity of the various components required for the expression of cell-mediated immunity. Although a number of newer in vitro tests for cell-mediated immunity in experimental animals are currently being developed and adapted for use in man, more information is needed to determine what functions these tests measure and their diagnostic usefulness in infectious diseases. We shall limit our consideration to those tests that have received the most study in this respect.

It goes without saying that B cell function should be evaluated by means of tests for antibody production against appropriate antigens.

5.1.1 Skin Tests

In man, the most important diagnostic test for cell-mediated immunity or delayed-type hypersensitivity is skin testing with the appropriate antigen. When skin tests are evaluated by an experienced observer for the quality (i.e., induration, oedema, time course) as well as the size of the reaction, they can provide valuable information. Tables IV and V summarize the majority of clinically useful skin tests in man.

Report of a WHO Scientific Group

635

Table IV. Skin test antigens used for assessing delayed hypersensitivity to infectious diseases in man 
a Evaluation of the skin test site should be made at 2-6 h to look for strong immediate hypersensitivity reactions, which may interfere with interpretation of the delayed response. $\mathrm{b}$ The absence of skin test reactivity in patients with minimal or histologically diagnosed disease (e.g., coccidioidomycosis, lepromatous leprosy, brucellosis, disseminated tuberculosis) is of prognostic value. However, it is important to realize that skin tests may be negative in patients with active disseminated disease (e.g., coccidioidomycosis, lepromatous leprosy, brucellosis, miliary tuberculosis, leishmaniasis), probably indicating defective cell-mediated immunity at that stage of the illness.

0 Blood for serological analysis must be drawn before the skin test is applied.

$\mathrm{d}$ Tween-stabilized PPD should be used; alternatively, if test is performed with material that needs to be reconstituted it must be used within 30-60 min.

636 Cell-Mediated Immunity and Resistance to Infection

Table V. Skin test antigens used for assessing $T$ cell function in man

Antigens Time of Reference

reaction, $h$ for usea

Contact sensitizers

Dinitrochlorobenzene (DNCB) 48-72 1

Dinitrofluorobenzene (DNFB)b 48-72

Picryl chloride 48-72 2

Intradermal antigens 0

Streptokinase-streptodornase (SKSD),

also known as varidase $\quad 24-48 \quad 1$

Keyhole limpet haemocyanin (KLH) 24-48 1

a References

WHO (1971) Primary immunodeficiencies. Bull. Wld Hlth Org., 45: 125.

Bullock, W. E. (1968) New Eogl. J. Med., 278, 298.

b DNFB may, if desired, be substituted for DNCB as described in reference 1. e Antigens listed in table IV may be used to assess $T$ cell function as outlined in section 5.1.4.

The absence of positive skin reactivity after testing with one of these antigens can indicate: (a) lack of prior exposure to antigen; (b) failure to develop and mobilize specific effector cells (i.e., sensitized lymphocytes); (c) blocking of T cell function by humoral factors; or (d) failure to develop inflammatory reactions. The last situation may be due either to the patient's inability to mobilize nonspecific effector cells, e.g., mononuclear phagocytes, or alternatively to a skin defect. To check this point, nonspecific irritants such as croton oil, benzylalkonium chloride, turpentine, or roebuck skin windows may be used to determine whether the subject can develop nonspecific inflammatory reactions. Conversely, the finding of positive reactivity at skin sites 24-48 $\mathrm{h}$ after testing does not of itself demonstrate delayed-type hyper sensitivity, since mononuclear chronic inflammatory cells are known to infiltrate sites damaged by strong immediate-type or Arthus reactions. This underscores the importance of making observations at 2-6 h after testing for evaluating later readings.

5.1.2 Biopsy

Clinically, the presence or absence of T or B cell development can be assessed by lymph node biopsy. In cases of relatively pure B cell deficiency, follicles and germinal centres would be absent from the cortex and Report of a WHO Scientific Group 
637

lymphoid elements could be expected to be depleted from the cortico-medullary junction. Depletion of lymphoid cells from the paracortical areas is seen in primary deficiencies of T cells. It may also occur secondary to infiltration of the paracortical area by pathogenic tissue, as in Hodgkin's disease and sarcoidosis, or by mycobacteria-laden macrophages, as in lep-romatous leprosy. Such replacement of the paracortical area may contribute in some cases to the patient's inability to mount a $\mathrm{T}$ cell response to contact sensitizers. In practice, lymph node biopsy is performed mainly to confirm impressions generated by functional immunological studies, to assist in clarifying difficult cases, or for research purposes. In man, biopsy of the skin is not very helpful in assessing the type of skin test reaction.

5.1.3 In vitro Tests [Bloom \& Glade, 1971]

The study of in vitro correlates of cell-mediated immunity is important for several reasons: (a) it can provide evidence confirming or invalidating skin test results; (b) it permits a separate analysis of the functional capacity of each of the cell populations involved; (c) it enables intrinsic deficits in $\mathrm{T}$ cell to be distinguished from deficits caused by blocking of this function by humoral factors; and (d) it obviates the need for introducing antigen into patients where this would be medically or ethically inadvisable.

(1) Identification of Cell Types

It is now possible to measure B lymphocytes, T lymphocytes, and monocytes readily in human peripheral blood on the basis of their unique surface characteristics (table I). Analysis of the mononuclear cell components becomes feasible after erythrocytes, granulocytes, and contaminating serum proteins have been removed by a simple procedure, such as Ficoll-isopaque centrifugation and washing. T lymphocytes form spontaneous rosettes (E rosettes) with washed sheep erythrocytes [Gondal et ah, 1972]. B lymphocytes have receptors for immunoglobulin and complement and form rosettes with sheep red blood cells (SRBC) coated with rabbit anti-SRBC antibodies and mouse complement [Bloom \& Glade, 1971]. Monocytes attach firmly to glass or plastic surfaces and can be distinguished, after the removal of non-adherent cells, by their ability to phagocytose carbon, latex, and other particles.

(2) Lymphocyte Reactivity

(a) Blast cell transformation [Oppenheim, 1968; Bloom, 1971]. The ability of lymphocytes to transform and incorporate labelled thymidine

638 Cell-Mediated Immunity and Resistance to Infection

following nonspecific stimulation with plant mitogens such as PHA and ConA or with mixed lymphocyte culture can be taken as a measure of T cell activity [Stobo et ah, 1972]. B lymphocytes appear to be selectively stimulated to transform nonspecifically by bacterial endotoxins such as Escheríchia coli or salmonella lipopolysaccharides [Gery et ah, 1972]. While this nonspecific transformation is an index of the functioning of the individual cell populations, there are numerous instances in which lymphocytes that can transform nonspecifically upon exposure to mitogens are unable to react with specific antigens. To evaluate the specific recognition of antigen by lymphocytes, blast cell transformation should therefore be tested with a variety of specific antigens (e.g., PPD, candidin, and lepromin). A great deal of evidence indicates that there is a general correlation between blast transformation upon exposure to specific antigens and the presence of delayed-type hypersensitivity in vivo. It must be remembered, however, that lymphocyte transformation can also occur with cells from previously sensitized individuals that undergo secondary antibody responses in vitro or from individuals with reaginic sensitization ( $\operatorname{IgE}$ ) to certain antigens. Furthermore, the degree of morphological 
transformation or thymidine incorporation is not directly related to the degree of sensitization or resistance to infection. The presence of humoral blocking factors can be tested for by their inhibition of blast cell transformation. Indeed, it is generally preferable to test for in vitro reactivity to antigens by using pooled human $\mathrm{AB}$ serum or heterologous sera, since antigen-antibody complexes can themselves under certain conditions induce blast transformation. If positive reactions are found in normal or heterologous sera but not in the presence of the patient's serum, blocking factors are probably present.

(b) Products of activated lymphocytes. It is possible for lymphocytes to have specific recognition function, e.g., the ability to undergo blast cell transformation, without having effector function. For example, lymphocytes from some patients with chronic mucocutaneous candidiasis can transform upon culture with Candida antigens but do not produce detectable amounts of MIF. Consequently, there is considerable interest in measuring products of activated lymphocytes (section 2.3.2.2). In man, the most frequently used functional test is cell migration. The principal systems examined have been: (a) direct migration inhibition of whole buffy coat leucocytes or of gelatin- or dextran-purified leucocytes; (b) migration inhibition of guineapig macrophages admixed to human peripheral lymphocytes $(9: 1$ or $4: 1)$; and (c) migration inhibition of guineapig macro-

Report of a WHO Scientific Group

639

phages by culture supernatants of antigen-stimulated human lymphocytes. Because these tests have been developed only recently, it has not yet been established whether the observed inhibition of migration truly reflects only cell-mediated immunity or whether it can also be produced by antibody-antigen complexes, cytophilic antibodies, and B lymphocyte function. It should be mentioned that in system (a) it is the migration of gran-ulocytes that is especially inhibited. In all the tests in man, particulate antigens appear to be more effective than soluble ones. Clearly, further work must be done before the usefulness of these tests in assessing T lymphocyte function and resistance to infection can be evaluated.

(c) Other functions. There is a critical need for an in vitro assay to measure the number of antigen-sensitive $\mathrm{T}$ lymphocytes in a given population. One recently developed assay, known as the virus plaque assay, has been used to enumerate antigen-sensitive lymphocytes from tuberculin-sensitive donors stimulated in vitro by PPD. The basis for the assay is the observation that normal lymphocytes do not produce infective virus whereas activated lymphocytes can do so; the number of lymphocytes activated to produce virus plaques in an indicator cell monolayer is easily determined. It has not been established whether the assay measures only, and all of, the activated T cells, or whether it can measure some activated B cells as well [Jiminez et al., 1971]. Model systems in experimental animals have demonstrated the feasibility of testing macrophages and lymphocytes for their ability to engender resistance to infection in vitro. When stimulated by specific antigen in vitro, lymphocytes hypersensitive to protein antigens and tuberculin have been able to confer nonspecific resistance on macrophages to in vitro infection with $\mathrm{L} \cdot$ isteria [Simon \& Sheagren, 1972]. A similar type of assay utilizing blood monocytes may prove useful in assessing macrophage function in human infectious disease [Godal el al., 1971].

5.1.4 Evaluation of Ability to Generate an Immune Response to a

New Antigen 1

The skin tests summarized in table IV can serve to evaluate the status of pre-existing delayed hypersensitivity responses. However, there is no question that some patients may show adequate 
responses to such antigens but be unable to generate a response to a new antigen. One must, therefore, be prepared to evaluate this function [Godal et al., 1971].

$<$ Bull. Wld Hlth Org. 45: 125 (1971).

640

Cell-Mediated Immunity and Resistance to Infection

While contact sensitizers such as dinitrochlorobenzene are usually employed (table V), an entirely satisfactory protein antigen for evaluating ability to generate a new delayed

hypersensitivity is not yet available, although keyhole limpet haemocyamin and schistosome egg antigens have been used for research purposes. Under well-defined, controlled conditions, an induced positive response to such antigens (provided that prior exposure can be ruled out) indicates that both the induction and effector functions of the cell-mediated immunity apparatus are intact from start to finish and essentially excludes the possibility of a deficiency in this system.

5.1.5 Standardization of Test Materials and Procedures There is an urgent need to improve the standardization of materials used in the tests described above, even in such classical procedures as the tuberculin skin test. It is also highly desirable that the test be performed and evaluated in standard fashion throughout the world. Suggestions for the performance of some tests have been made by other groups convened by WHO.1

References

Bloom, B. R. (1971) Adv. Immunol., 13, 101

Bloom, B. R. \& Glade, P. R. (1971) In vitro methods in cell-mediated immunity, New York, Academic Press. Gery, I., Krüger, J. \& Spiesel, S. Z. (1972) J. Immunol., 108, 1088 Godal, T., Rees, R. J. W. \& Lamvik, J. O. (1971) Clin. exp. Immunol., 8, 625 Gondal, M., Holm, J. \& Wigzell, H. (1972) J. exp. Med., 136, 2 Jiminez, L., Bloom, B. R., Blume, M. R. \& Oettgen, H. F. (1971) J. exp. Med.,

133, 740 Oppenheim, J. J. (1968) Fed. Proc, 27, 21 Simon, H. B. \& Sheagren, J. N. (1972) Cell. Immunol., 4, 163 Stobo, J. D., Rosenthal, H. S. \& Paul, W. E. (1972) J. Immunol., 108, 1 5.2 Augmentation of the Immune Response

Patients who fail to resist certain infections because of a defect in specific cell-mediated immunity might benefit from active immunization by methods known to increase this type of immunity. Possible procedures in-

i Bull. Wld Hlth Org. 43: 879 (1970); Bull. Wld Hlth Org. 45: 125 (1971); Wld Hlth Org. techn. Rep. Ser., No. 496 (1972).

Report of a WHO Scientific Group

641

elude incorporating microbial antigen in mycobacterial adjuvant, mixing the antigen with living BCG, or modifying it chemically in ways known to enhance cell-mediated immune responses. (The use of complete Freund's adjuvant in man cannot be recommended because of severe local reactions.) The ultimate success of such procedures may depend on whether the host is in a state of specific unresponsiveness to the relevant microbial antigens or whether he has undergone immune deviation (see section 2.4.2). Recent experimental evidence shows that a regional node draining the site of a normal allogeneic lymphocyte transfer reaction may show an enhanced antibody response to an unrelated antigen. However, its effects on the cell-mediated immune response remain to be determined. Because of the known hazards of injecting living allogeneic cells, the effects of cell extracts should be investigated. 
Cell-mediated immune responses in man may be transferred from one person to another by administering either peripheral blood lymphocytes (as may frequently be demonstrated after whole blood transfusions) or bone-marrow cells. The measurable responses after transfer include positive delayed hypersensitivity skin tests, antigen-specific blast transformation, and MIF production. These effects are transient because of the inevitable rejection of the donor's cells by the host. Clinical improvement has been reported in patients with chronic mucocutaneous candidiasis and vaccinia gangrenosa following the transfer of lymphocytes from immune donors. Thymus-deficient children have been transplanted with fetal thy-mus, with resultant amelioration of their progressive infections. Longer-term follow-up evaluations will be necessary to determine the benefits of this type of reconstitution. Permanent reconstitution of the immune systems of patients with bone-marrow deficiency (due either to primary stem-cell deficiencies or acquired bone-marrow failure as in aplastic anaemia or leukaemia) by allogeneic bone-marrow transplantation has been complicated by fatal graft-versus-host disease. Again, more work is required to assess the effects of this type of transplantation, but the possibility remains that useful applications may be developed in the future.

5.2.3 Transfer Factor

In man, frozen and thawed extracts of leucocytes from donors with strong delayed hypersensitivity have been demonstrated to induce positive delayed-type skin reactions to bacterial antigens in previously negative recipients. The duration of reactivity in recipients has varied from weeks or months to years. Since the active material - called transfer factor - is pre642 Cell-Mediated Immunity and Resistance to Infection sent in low molecular weight dialysates of the leucocyte extracts as well, the use of dialysates is preferred since it obviates the danger of transferring viruses, e.g., hepatitis virus. Thus far no reproducible animal models or in vitro systems have been developed for studying transfer factor. Its possible mechanisms of action include: (a) the passive transfer of specific immunological information via nucleic acids that somehow become incorporated into the normal recipient lymphocytes; (b) a 'super-antigen' effect, i.e., enhanced active sensitization of recipients by antigenic determinants in the leucocytes complexed with nucleic acids; and (c) nonspecific augmentation of the specific $\mathrm{T}$ cell reactivity present at subthreshold levels in recipients. Significant clinical improvement following the administration of transfer factor has been seen in some patients with Wiskott-Aldrich syndrome and in chronic mucocutaneous candidiasis, but the number of cases studied is too small to evaluate the effectiveness fully at this time. The possible therapeutic usefulness of transfer factor in immunodeficiency diseases, indeterminate leprosy, generalized herpes simplex, varicella, herpes zoster, and coccidioidomycosis is currently being tested in controlled blind studies. It should be pointed out that while no evidence exists at present for any direct systemic toxic effects of dialysable transfer factor in recipients, untoward clinical effects could occur, e.g., reversal reactions in patients with lepromatous leprosy.

6. Prophylaxis

Much of this report has dealt with the mechanisms whereby cell-mediated immune responses can contribute to the capacity of a host to resist certain infections. A thorough analysis of these mechanisms is in general possible only through the use of experimental animal models. Data pointing to the existence and effectiveness of cell-mediated immune reactions in a number of human diseases have also been considered. The report has emphasized the difficulties of extrapolating these studies to man. Nevertheless, there is inferential evidence, some of it very strong, that effective resistance to many human diseases depends largely or even entirely on cellmediated immunity. The application of modern immunological concepts and techniques to the 
prophylaxis of many common diseases that are at present poorly controlled should be given high priority in national and international health programmes. Among the common diseases in Report of a WHO Scientific Group

643

which cell-mediated immunity appears to be important and for which vaccines are not available or not fully effective are typhoid, leprosy, syphilis, and a wide variety of protozoal and metazoal diseases (e.g., leish-maniasis, schistosomiasis, hookworm infestations, and possibly malaria and trypanosomiasis). Diseases in which the role of cell-mediated immunity is even less firmly established but for which no satisfactory vaccines are available include trachoma, typhus, dengue, tick-borne encephalitis, hepatitis (A and B) and the chonic forms of gonorrhoea. Future research may show that diseases caused by slow viruses and horizontally-transmitted oncogenic viruses also belong to this list.

There are several general requirements for the development of effective new vaccines. There must be clinical, epidemiological, or experimental evidence that resistance to the disease can be acquired and is im-munologically mediated; and a model infection should be sought in which the major clinical, pathological, and immunological features of the human disease can be reproduced and analysed. The roles of cell-mediated immunity and humoral immunity must be clearly separated and their relative importance evaluated. The antigens (or stages in the life-cycles of parasites) eliciting the most effective responses should be identified. A convenient source of adequate quantities of the appropriate antigens must also be available. The value of any vaccine that fails to induce the type of immune response involved in resistance must be seriously questioned. If live, the vaccine should be incapable of producing a progressive infection in normal subjects, should be devoid of potentially immunogenic tissue components, and should not cause objectionable local reactions. The vaccine should be stable on storage under the various conditions obtaining in different parts of the world, and its potency should be able to be assayed by suitable methods.

A general, effective, and safe method is needed for inducing cell-mediated immunity to constituents of killed vaccines, especially virus vaccines. This would obviously be of importance in mass vaccination programmes; in the small minority of the population that may be immunolog-ically compromised, the use of live attenuated vaccines might result in progressive infections. It would also obviate the potential danger of mutation. Devising such a method will require much more extensive knowledge of the mechanisms controlling the development of cellmediated immune responses to different modes of immunization, for example, those affecting the response to oral vaccines. It may also require more information concerning the life-span of the specific effectors of cell-mediated im-

644 Cell-Mediated Immunity and Resistance to Infection munity, particularly in man, in relation to the persistence of microbial antigens in the body and the duration of protection. A search must be made for adjuvants that stimulate cell-mediated immunity and that are safe for use in man. The use of combined vaccines inducing cell-mediated immunity is also desirable and should be explored.

Cost/benefit analyses of past developments in immunization and in medical research generally [Waksman, 1971; Fudenberg, 1972] indicate that money spent on a combined programme of basic and clinical research to solve a particular disease problem, especially one already known in principle to be soluble, yields a very great financial benefit.

References 
Fudenberg, H. H. (1972) I. Lab. clin. Med, 79, 353 Waksman, B. H. (1971) I. Immunol., 707, 617

Annex

Further Background Literature

Nonspecific Effector Cells (Section 2.2.2) Furth, R. van, ed. (1970) Mononuclear phagocytes, Oxford, Blackwell

Molecular Mediators (Section 2.3.2)

Bloom, B. R. (1971) In vitro approaches to the mechanism of cell-mediated immune responses, Adv. Immunol., 13, 101

Bloom, B. R. \& Glade, P. R. (1971) In vitro methods in cell-mediated immunity, New York, Academic Press

David, J. R. \& David, R. R. (1972) Progr. Allergy, 16, 300

Lawrence, H. S. \& Landy, M. (1970) Mediators of cellular immunity, New York, Academic

Press

Nelson, D. S. (1969) Macrophages and immunity, Amsterdam, North-Holland Publishing

Company

Interaction between Antibody-Mediated and Cell-Mediated Immunity (Section 2.4) Turk, J. L. \& Parker, D. (1973) Further aspects of the suppression of B-lympho-cytes in delayed hypersensitivity: a possible expanation for Jones-Mote hyper-sensitivity. Immunology (In press) Turk, J. L., Parker, D. \& Poulter, L. W. (1972) Functional aspects of selective depletion of lymphoid tissue by cyclophosphamide, Immunology, 23, 493 Voisin, G. A. (1971) Progr. Allergy, 75, 328

Report of a WHO Scientific Group

645

Virus Infections (Section 3.2)

Allison, A. C. (1973) Ann. Inst. Pasteur, 123, 585

Blanden, R. V. (1970) Mechanisms of recovery from a generalized viral infection: mousepox. I. The effects of antithymocyte serum, J. exp. Med., 132, 1035

Blanden, R. V. (1971) Mechanisms of recovery from a generalized viral infection: mousepox. II. Passive transfer of recovery mechanisms with immune lymphoid cells. J. exp. Med., 133, 1074 Blanden, R. V. (1971) Mechanisms of recovery from a generalized viral infection: mousepox. ПТ. Regression of infectious foci. J. exp. Med., 133, 1090

Epstein, L. B., Cline, M. J. \& Merigen, T. C. (1971) PPD-stimulated interferon: in vitro macrophage-lymphocyte interaction in the production of a mediator of cellular immunity, Cell. Immunol., 2, 602

Glasgow, L. A. (1970) Cellular immunity in host resistance to viral infections, Arch, intern.

Med., 126, 125

Lundstedt, C. (1969) Interaction between antigenically different cells: virus-induced cytotoxicity by immune lymphoid cells in vitro, Acta. path, microbiol. scand., 75, 139

Mycoplasma Infections (Section 3.3) Denny, F. W., TAYLOR-Robinson, D. \& Allison, A. C. (1972) The role of thymus-dependent immunity in Mycoplasma pulmonis infections of mice, J. med. Microbiol., 5, 327

Fungus Infections (Section 3.4) Gentry, L. O. \& Remington, J. S. (1971) Resistance against cryptococcus conferred

by intracellular bacteria and protozoa, J. infect. Dis., 123, 22 Lehner, T., Wilton, J. A. \& Ivanyi, L. (1972) Immunodeficiencies in chronic muco- 
cutaneous candidosis, Immunology, 22, 775 Lehrer, R. I. (1970) Measurement of candicidal activity of specific leukocyte types

in mixed cell populations, Infect. Immun., 2, 42

Protozoal Infections (Section 3.5) Malaria

Barker, L. R. \& Powers, K. G. (1971) Impairment of antibody responses and recovery in malarial rodents by anti-lymphocytic serum, Nature, 229, 429

Brown, I. N. (1969) Immunological aspects of malaria infection, Adv. Immunol., 11, 267

Brown, K. N. (1971) Protective immunity to malaria provides a model for the survival of cells in an immunologically hostile environment, Nature, 230, 160

Brown, I. N., Allison, A. C. \& Taylor, R. B. (1968) Plasmodium berghei infections in thymectomized rats, Nature, 219, 292

Brown, K. N., Brown, I. N. \& Hills, L. A. (1970) Immunity to malaria. I. Protection against Plasmodium knowlesi shown by monkeys sensitized with drug-suppressed infections and by dead parasites in Freund's adjuvant, Exp. Parasit., 28, 304

Criswell, B. S., Butler, W. T., Rossen, R. D. \& Knight, V. (1971) Murine

646

Cell-Mediated Immunity and Resistance to Infection

malaria: the role of humoral factors and macrophages in destruction of parasitized erythrocytes, J. Immunol., 107, 212

Jerusalem, C, Weiss, M. L. \& Poels, L. (1971) Immunologic enhancement in malaria infection (Plasmodium berghei), J. Immunol., 107, 260

Kass, L., Willerson, D., jr., Rieckmann, K. H. \& Carson, P. E. (1971) Blastoid transformation of lymphocytes in falciparum malaria, Amer. J. trop. Med. Hyg., 20, 195

McGregor, I. A. (1971) Immunity to plasmodial infections; consideration of factors relevant to malaria in man, Int. Rev. trop. Med. 4, 1

Nussenzweig, R. S. (1967) Increased nonspecific resistance to malaria produced by administration of killed Corynebacterium parvum, Exp. Parasit., 27, 224

Phillips, R. S. (1970) Plasmodium berghei. Passive transfer of immunity by antisera and cells, Exp. Parasit., 27, 479

Roberts, J. A. \& Tracey-Patte, P. (1969) Adoptive transfer of immunity to Plasmodium berghei, J. Protozool., 16, 728

Spira, D. T., Scherman, P. H. \& Gaines, E. (1971) Antithymocyte serum effects on Plasmodium berghei in rats, Immunology, 19, 759

Stechschulte, D. J. (1969) Plasmodium berghei infection in thymectomized rats, Proc. Soc. exp. Biol. Med., 131, 748

Stechschulte, D. J. (1969) Cell-mediated immunity in rats infected with Plasmodium berghei, Milit. Med., 134, 1147

Trypanosomiasis

Mansfield, J. M. \& Kreier, J. P. (1972) Tests for antibody- and cell-mediated hy-persensitivity to trypanosome antigens in rabbits infected with Trypanosoma congolense, Infect. Immun., 6, 62

Tizard, I. R. \& Soltys, M. A. (1971) Cell-mediated hypersensitivity in rabbits infected with Trypanosoma brucei and Trypanosoma rhodesiense, Infect. Immun., 4,674

Leishmaniasis

Aikyama, H. J. and Haight, R. D. (1971) Interaction of Leishmania donovani and hamster peritoneal macrophages, Amer. J. trop. Med. Hyg., 20, 539 
Blewett, T. M., Kadivar, D. M. H. \& Soulsby, E. J. L. (1971) Cutaneous leishmaniasis in the guinea pig, Amer. J. trop. Med. Hyg., 20, 546

Bray, R. S. \& Bryceson, A. D. M. (1968) Cutaneous leishmaniasis of the guinea pig, Lancet, ií, 898

Bryceson, A. D. M., Preston, P. M., Bray, R. S. \& Dumonde, D. C. (1972) Experimental cutaneous leishmaniasis. II. Effects of immunosuppression and antigenic competition on the course of infection with Leishmania enriettii in the guinea pig, Clin. exp. Immunol., 10, 305 Metazoal Infections (Section 3.6) Bagai, R. C. \& Subrahmanyam, D. (1970) Nature of acquired resistance to filarial

infection in albino rats, Nature, 228, 682 Dineen, J. K. \& Adams, D. B. (1971) The role of the recirculating thymus-depen-

Report of a WHO Scientific Group

647

dent lymphocyte in resistance to Trichostrongylus colubriformis in the guinea-pig, Immunology, 20, 109

Gershon, R. K. \& Kondo, K. (1971) Dependence of concomitant tumour immunity on continued antigenic stimulation, J. nat. Cancer Inst., 46, 1169

Gershon, R. K. \& Kondo, K. (1971) Dependence of concomitant tumour immun-tumour-bearing hamsters, Nature, 213, 674

Jarrett, E. E. E. \& Urquhart, G. M. (1971) The immune response to nematode infections, Int. Rev. trop. Med., 4, 53

Keller, R. \& Keist, R. (1972) Protective immunity to Nippostrongylus brasiliensis in the rat, Immunology, 2, 767

Keller, R. \& Ogilvie, B. M. (1972) The effects of drugs on worm expulsion in the

Nippostrongylus brasiliensis infected rat: a discussion of the interpretation of drug action, Parasitology, 64, 217

Lichtenberg, F. von (1970) In: Immunological aspects of parasitic infections, Washington, Pan American Health Organization, Scientific Publication No. 150, p. 107

Ogilvie, B. M. \& Jones, V. E. (1971) Parasitological review: Nippostrongylus brasiliensis: a review of immunity and host-parasite relationship in the rat, Exp. Parasit., 29, 138

Rothwell, T. L. W. \& Dineen, J. K. (1972) Cellular reactions in guinea-pigs following primary and challenge infection with Trichostrongylus colubriformis with special reference to the roles played by eosinophils and basophils in rejection of the parasite, Immunology, 22, 733

Rothwell, T. L. W., Dineen, J. K. \& Love, R. G. (1971) The role of pharmacologically active amines in resistance to Trichostrongylus colubriformis in the guinea-pig, Immunology, 21, 925 Smithers, S. R. (1972) Recent advances in the immunology of schistosomiasis, Brit, med. Bull. 28,49

Wagland, B. M. \& Dineen, J. K. (1965) The cellular transfer of immunity to Trichostrongylus colubriformis in an isogenic strain of guinea-pig, Austr. J. exp. Biol. med. Sci, 43, 429

Warren, K. S. \& Domingo, E. O. (1970) Granuloma formation around Schistosoma mansoni, S. haematobium, and S. ;aponicum eggs: size and rate of development, cellular composition, crosssensitivity, and rate of egg destruction, Amer. J. trop. Med. Hyg., 19, 292

Warren, K. S., Cook, J. A. \& Jordan, P. (1972) Passive transfer of immunity in human Schistosomiasis mansoni: effect of hyperimmune anti-schistosome y-globulin on early established infections, Trans, roy. Soc. trop. Med. Hyg., 66, 65 
Aberrant or Defective Functioning of Cell-Mediated Immunity (Section 4) Turk, J. L. (1967)

Delayed hypersensitivity, Amsterdam, North-Holland Publishing Company

Nonspecific Unresponsíveness (Section 4.1) Levene, G. M., Wright, D. J. M. \& Turk, J. L.

(1971) Cell-mediated immunity and lymphocyte transformation in syphilis, Proc. roy. Soc. Med., 64,426

648 Cell-Mediated Immunity and Resistance to Infection

X-Rays, Cytotoxic Drugs, and Corticosteroids (Section 4.1.4) Hart, P. D., Russel, E. \&

Remington, J. S. (1969) The compromised host and

infection. II. Deep fungal infection, J. infect. Dis., 120, 169 Swanson, M. A. \& Schwartz, R. S.

(1967) Immunosuppressive therapy: the relation

between clinical response and immunologic competence, New Engl. J. Med.,

277,163

Diseases of the Reticuloendothelial System (Section 4.1.5) Miller, D. G. (1962) Patterns of immunological deficiency in lymphomas and leukaemia, Ann. intern. Med., 57, 703

Antigen-Specific Unresponsiveness (Section 4.2) Turk, J. L. \& Bryceson, A. D. M. (1971)

Immunological phenomena in leprosy and related diseases, Adv. Immunol. 13, 209

Granuloma Formation (Section 4.3) Turk, J. L. (1971) Granuloma formation in lymph nodes,

Proc. roy. Soc. Med., 64, 18

Diagnostic Measures Based on Cell-Mediated Immune Reactions (Section 5.1) Bellanti, J.

(1972) Immunology, New York, Saunders Turk, J. L. (1968) Delayed hypersensitivity,

Amsterdam, North-Holland Publishing

Company

Augmentation of the Immune Response (Section 5.2)

Gober, L. L., Friedman-Kien, A. E., Hauell, E. A. \& Vilcek, J. (1972) Suppression of the intracellular growth of Shigella flexneri in cell cultures by interferon preparations and polyinosinic-polycytidylic acid, Infect. Immun., 5, 370

Remington, J. S. \& Merigan, T. C. (1970) Synthetic polyanions protect mice against intracellular bacterial infection, Nature, 226, 361

Vilcek, J. \& Kahiel, R. I. (1970) Action of interferon and its inducers against non-viral infectious agents, Arch, intern. Med. 726, 69

Mathé, G. et al. (1969) Active immunotherapy for acute lymphoblastic leukaemia, Lancet, /, 691 1973;044:589

Wilhelm Loeffler $\dagger$ 


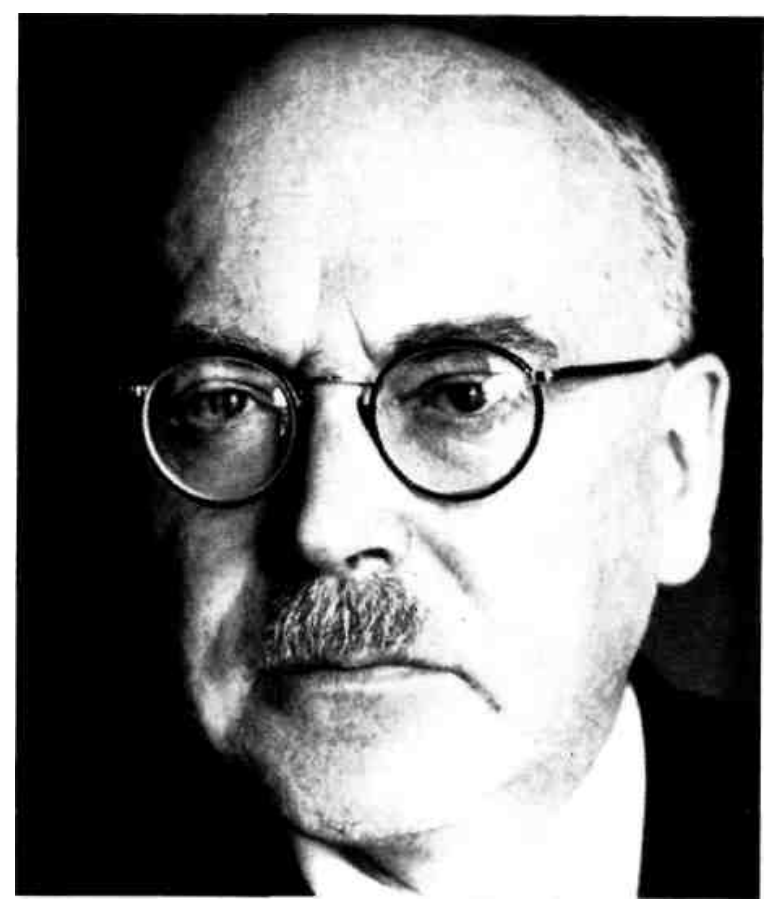

W. Loeffler, the well known clinician, scientist and teacher died in Zurich on November 25, 1972 at the age of 86.

He was born in Basle and was particularly influenced during his preclinical studies by R. Chodat, the botanist in Geneva, and G. von Bunge, the biochemist in Basle. After graduation he was urged by R. Staehelin to do postgraduate work in biochemistry. He did this in Strasbourg with F. Hofmeister. There, his scientific work centered mainly in experiments concerning the formation of urea. This was followed by years of clinical and scientific experience in internal medicine under R. Staehelin in Basle and a period of training in pathology with E. Hedinger. In 1921 he was made chief of the Medical Policlinic at the University of Zurich. Subsequently, he became director of the Department of Medicine at the University of Zurich. He held this post from 1937 to 1957.

650

Obituary

Already in 1923, together with A. Alder, he introduced routine serial X-ray fluoroscopy into the medical policlinic. With this new method of examination he discovered the transient pulmonary eosinophilic infiltration which is known today as Loeffler's syndrome. Working jointly with A. Essellier, the first etiologic factor for this syndrome was recognized as ascaris larvae which pass through the lung during their developmental cycle. Later, other causes were found to include reactions to other parasites as well as to certain drugs and other chemicals. The description of fibroplastic parietal endocarditis with blood eosinophilia followed in 1936.

During his entire research and teaching career W. Loeffler was especially interested in the epidemiology, early diagnosis, prophylaxis and treatment of tuberculosis. With great success, he applied the full force of his socio-political capabilities in this area of medicine.

In the field of research W. Loeffler allowed his associates a wide variety in their choice of subjects. With this, he had the extraordinary ability to quickly perceive the relevant problems in every field and offer constructive suggestions and stimulation. Despite his personal interest in cardiopulmonary diseases, W. Loeffler intensively promoted the study of hematology in his 
clinic (P. Frick, R. Hegglin, F. Koller, A. Loeliger, H. R. Marti, S. Moeschlin, K. Rohr). This was in part certainly influenced by the tradition of his immediate predecessor O. Naegeli. In other areas, such former associates as E. Hanhart, M. Holzmann, M. Kartagener, W. Siegenthaler and F. Wuhrmann are to be mentioned.

In clinical and research work he accepted not only the thoughts and conclusions derived from strict deductive thinking, but also allowed intuition which has led to many discoveries in medicine. For him, medicine was not just applied natural science, and even less natural science itself. He stressed the importance of the arts and sciences and historical values in medical thinking. Despite the tremendous advances in the basic sciences and technical fields, the duties of the physician as a personality, as valid in the days of Hippocrates, had hardly changed at all for Loeffler.

Professor W. Loeffler shall always be remembered by his associates, students and endless audiences of physicians and laymen for his stimulating lectures. These were originally formulated and displayed a very definite sense of humour and accentuated the pertinent. He applied his well founded knowledge of the classics, creative arts as well as french and english literature to good advantage.

W. Loeffler is well known to the readers of the International Archives of Allergy and Applied Immunology as one of its founders.

Until the last days of his richly filled life, W. Loeffler, with all his wisdom, continued to involve himself with modern problems. Together with A. Grumbach he organized and presided over the first International Congress of Allergology held in Zurich in 1951. R. Hoigné, Bern 1973;044:649

\section{Book Review}

P. Kallós, B. H. Waksman and A. de Weck (eds.): Progress in Allergy. Vol. 16. Karger, Basel 1972. XII + 486 pp., 52 fig., 31 tab., 2 cpl.; sFr. 128.- I US \$ 35.85 I DM 114.- /£ 14.10.

The present volume 16 of 'Progress in Allergy' focusses on most active areas of research. It is heavily weighted in favor of cellular immunology. J. R. David and R. R. David contributed a most comprehensive and elegantly written survey on the subject of mediators of cellular immune reactions ('Cellular Hypersensitivity and Immunity. Inhibition of Macrophage Migration and the Lymphocyte Mediators'). The reader finds himself confronted with a huge mass of data arranged in a masterly and sovereign way which easily brings him up to date in this complex yet extremely important material. Not less important for the understanding of current immunological thinking is the Clamans and Mosier article on 'Cell-Cell Interactions in Antibody Production'. It beautifully cites the experimental evidence that led to the concept of the cooperative effort between thymus-derived $\mathrm{T}$ lymphocytes and bursa-dependent bone marrow-derived $\mathrm{B}$ lymphocytes in antibody production. It is with some regret that one notes that the literature has not been covered beyond October 1970, so that important new developments in this rapidly advancing field are not accounted for (e.g. the question of $\mathrm{T}$ cell mediators affecting the function of the immune response). This, of course, by no means invalidates the article, one rather wonders with respect to future reviews whether a short note added in proof might not be helpful.

This has been done in Schlesinger's article on 'Antigens of the Thymus'. This article will prove very useful to the reader who wants to gain an insight as to how immunology approaches the question of characterization of different lymphocyte populations, and thereby understand the 
evolution of immunological competence. It gives the basis for an understanding of the article of Claman and Mosier which complement each other in a wellcome fashion.

On the humoral side, one finds 3 articles. The Tomasi and Grey contribution on 'Structure and Function of Immunoglobulin A' surveys the current state of knowledge on IgA which has during the past few years gained great interest as a weapon against local infections. Besides giving a survey on immunochemistry of $\operatorname{IgA}$, the practical aspects with respect to biological activity, vaccination, and deficiency diseases are covered. The chapter by Osler and Siraganian on 'Immunological Mechanisms of Platelet Damage' deals with 'classical' immune mechanisms of humoral type but it opens new aspects for a deeper insight into the mechanisms involved which are more complicated than hitherto assumed. The role of the platelets in activation of alternate complement pathway and the interaction of platelets with baso-phils are recent developments which one will see set in perspective. The section by Faulk and Humans on 'Recent Developments in Immunofluorescence' reviews this all-important technique of immunological research and will surely help to standardizing methods in various laboratories and thereby make experimental data more comparable.

One must congratulate the editors and the publisher for compiling this extremely

valuable volume in this series. Hahn, Freiburg i. Br. 1973;044:650

News Item

Robert Koch Prize 1972

The Robert Koch Prize and the Robert Koch Medal for 1972 have been awarded to two members of the Collegium Internationale AUergologicum, Dr. L. Berrens (Utrecht) and Prof. A. L. de Weck (Bern) for their investigations in the field of allergy. The official ceremony, presided over by the Deputy Minister of Health of the German Federal Republic, took place in Bonn on January 26, 1973. 1973;044:652 